Review Article

\title{
Curcumin, a Multifaceted Hormetic Agent, Mediates an Intricate Crosstalk between Mitochondrial Turnover, Autophagy, and Apoptosis
}

\author{
Nathan Earl Rainey $\mathbb{D}^{1},{ }^{1}$ Aoula Moustapha, ${ }^{1,2}$ and Patrice Xavier Petit $\mathbb{D}^{1}$ \\ ${ }^{1}$ SPPIN, Saints-Pères Paris Neuroscience Institute, CNRS UMR 8003 Paris-City University, Campus Saint-Germain, \\ Team "Mitochondria, Apoptosis, And Autophagy Signalling", 45 Rue des Saints-Pères, 75006 Paris, France \\ ${ }^{2}$ Pharmacology and Toxicology Department, Faculty of Pharmacy, Homs., Syria \\ Correspondence should be addressed to Patrice Xavier Petit; patrice.petit@inserm.fr
}

Received 23 November 2019; Revised 1 March 2020; Accepted 25 May 2020; Published 20 July 2020

Academic Editor: Tullia Maraldi

Copyright (C) 2020 Nathan Earl Rainey et al. This is an open access article distributed under the Creative Commons Attribution License, which permits unrestricted use, distribution, and reproduction in any medium, provided the original work is properly cited.

\begin{abstract}
Curcumin has extensive therapeutic potential because of its antioxidant, anti-inflammatory, and antiproliferative properties. Multiple preclinical studies in vitro and in vivo have proven curcumin to be effective against various cancers. These potent effects are driven by curcumin's ability to induce G2/M cell cycle arrest, induce autophagy, activate apoptosis, disrupt molecular signaling, inhibit invasion and metastasis, and increase the efficacy of current chemotherapeutics. Here, we focus on the hormetic behavior of curcumin. Frequently, low doses of natural chemical products activate an adaptive stress response, whereas high doses activate acute responses like autophagy and cell death. This phenomenon is often referred to as hormesis. Curcumin causes cell death and primarily initiates an autophagic step (mitophagy). At higher doses, cells undergo mitochondrial destabilization due to calcium release from the endoplasmic reticulum, and die. Herein, we address the complex crosstalk that involves mitochondrial biogenesis, mitochondrial destabilization accompanied by mitophagy, and cell death.
\end{abstract}

\section{The Structural Chemistry of Curcumin Related to Its Biological Effects}

Curcumin, or (1E,6E)-1,7-bis (4-hydroxy-3-methoxyphenyl)1,6-heptadiene-3,5-dione, is a symmetric molecule also called diferuloyl methane (MW $368.38 \mathrm{~g} \cdot \mathrm{mol}^{-1}$ ) extracted from the dietary spice curcuma, historically used in Asian food and traditional medicine [1]. As previously described curcumin $[2,3]$ three chemical entities structure the molecule:2 omethoxyphenol connected by a seven-carbon linker with an $\alpha, \beta$-unsaturated diketone moiety (Figure $1(\mathrm{a})$ ). The resonance structure inside the molecule is responsible for its participation in many electron transfer reactions.

Almost a century after its isolation from turmeric, Lampe in 1913 [4] published the synthesis of curcumin in a series of steps starting with carbomethoxyferuloyl chloride and ethyl acetoacetate. Later, Pabon described a simple method for the synthesis of curcumin with high yields that is still in use today [5]. Patented processes indicating the use of $\mathrm{B}_{2} \mathrm{O}_{3}$, trialkylborate, and $n$-butylamine along with inert organic amide solvents have since improved yields [6-8] (Figure 2(a)). Highperformance liquid chromatography (HPLC) is efficiently used for the detection and quantification of curcumin [9].

Curcumin is an electron donor and stabilizes its chemical structure by redistribution and resonance of the $\pi$ electron cloud [1]. The extended conjugation confers UV-visible absorption properties $(250-270 \mathrm{~nm}$ and $350-450 \mathrm{~nm})$. So, curcumin fluoresces with emission starting at $470 \mathrm{~nm}$. These optical properties are used for the isolation and purification of curcumin by various techniques and fluorescence which enable the monitoring of very low amounts of curcumin and related metabolites in plasma and urine in the range of $2.5 \mathrm{ng} / \mathrm{mL}$ [9-11]. Curcumin can also be excited at $488 \mathrm{~nm}$ with a lower fluorescent yield emission in the $500-550 \mathrm{~nm}$ 


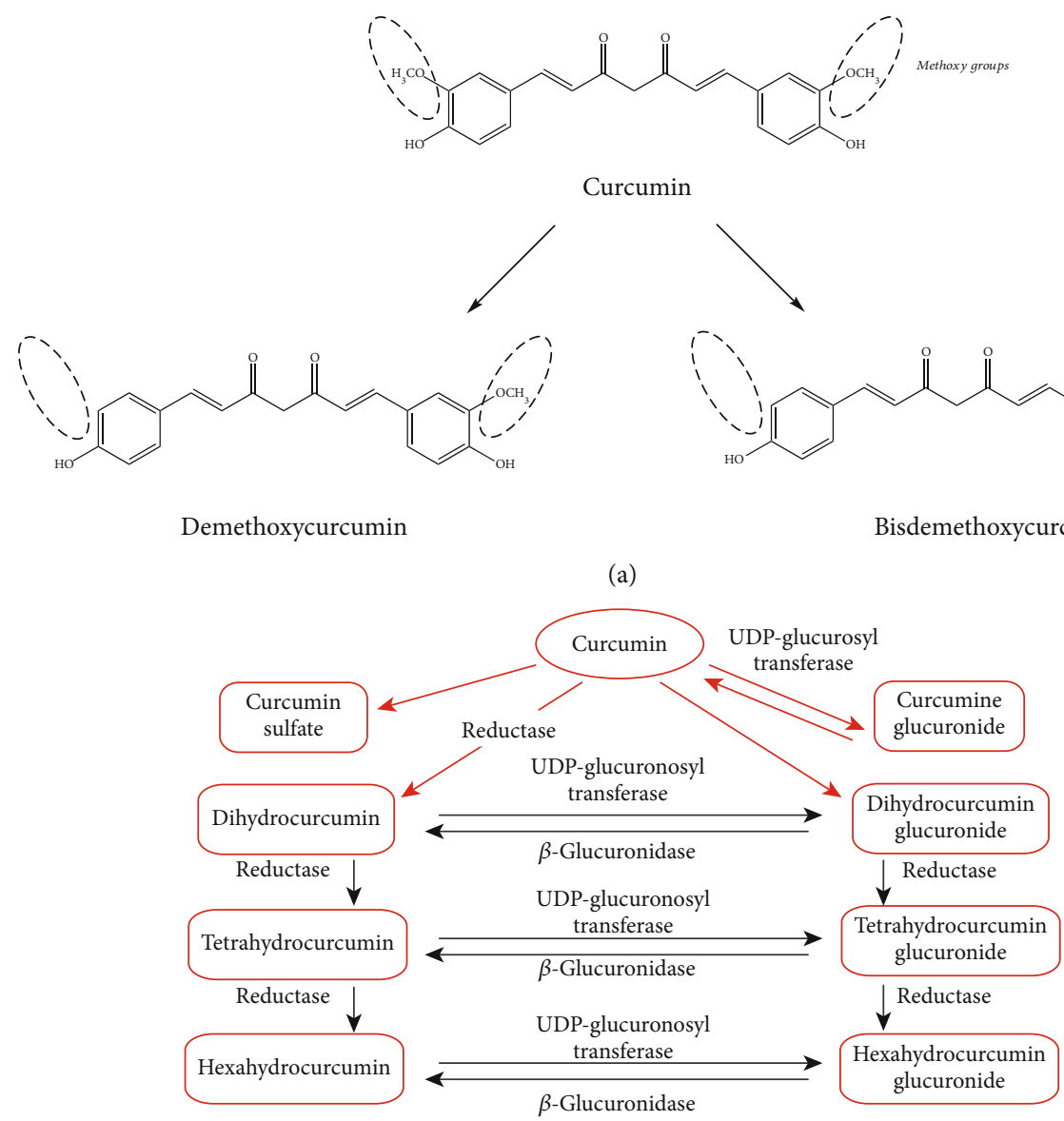

(b)

FIGURE 1: Curcumin structure and secondary metabolites. Schematic interpretation reproduced from Priyadarsini K.I. with permission [1] showing naturally occurring curcuminoids (a) and major metabolites produced once ingested (b).

range for detection in flow cytometry and confocal microscopy as we described before [2]. Curcumin is a weak Brönsted acid, with three labile protons and accordingly three pKa values - which can be estimated by both NMR and absorption spectrometry-corresponding to three prototropic equilibria (Figure 2(b)).

A key active site of curcumin for biological reactions is the diketo group, which acts as the primary hydrogen affinity site at physiological $\mathrm{pH}[1,12]$. The diketo group displays keto-enol tautomerism to reach prototropic equilibrium [12]. In addition to this enol (A-OH) site, the two phenol$\mathrm{OH}$ locations appear to be more resistant to oxidation, but can undergo oxidation by electron transfer and hydrogen abstraction at more alkaline $\mathrm{pH}$. Curcumin is a hydrophobic molecule with a $\log P$ value of 3.0 at neutral $\mathrm{pH}$ [13]. Therefore, curcumin is not easily soluble in physiological media and exhibits poor distribution and bioavailability [14].

As a whole, curcumin acts as a hydrophobic reducing agent and scavenges many reactive oxygen species (ROS) (Figure 2(c)) [14]. Phenoxyradicals formed can be regenerated by other $\mathrm{H}^{+}$donors like ascorbic acid, for consecutive ROS elimination. Curcumin is as efficient in the removal of radicals as well-known antioxidants-thiols, vitamin $\mathrm{A}$, vitamin $\mathrm{C}$, and vitamin $\mathrm{E}$ - and mimics the function of superoxide dismutase [13].
The hydrogen donor site $\alpha, \beta$-unsaturated $\beta$-diketo moiety is also considered the breakdown point in the curcumin structure, where curcumin hydrolysis and degradation take place essentially in aqueous media. Indeed, ninety percent of curcumin degrades within half an hour in water [15], giving rise by hydrolysis to several products, i.e., ferulic acid, ferulic aldehyde, and feruloyl methane.

The rate of curcumin hydrolysis significantly decreases when the diketo reaction site is complexed to lipids, peptides, proteins, surfactants, and other molecular structures, a situation occurring both in biological fluids and within cells [16]. Accordingly, curcumin solutions are more stable in culture media containing fetal calf serum (FCS), and evidence shows that once curcumin is in the bloodstream, hydrolytic degradation is abolished since the diketo function is occupied through binding to plasma proteins and other biomolecules [17]. On the other hand, even though hydrolytic degradation of curcumin scarcely happens in vivo, it is subject, once absorbed, to fast enzyme-mediated metabolism leading to hydrophilic metabolites [15]. Pathways have been proposed for the metabolism of hydrophobic curcumin to hydrophilic metabolites [13].

Curcumin is reduced to tetra-, hexa-, and octa-hydrocurcumins, and its two phenolic groups are conjugated to produce either curcumin glucuronide or curcumin sulfate [15] (Figure 1(b)). 
$\underbrace{\mathrm{OH}}_{\mathrm{CH}_{3}}+\mathrm{B}_{2} \mathrm{O}_{3} \longrightarrow$

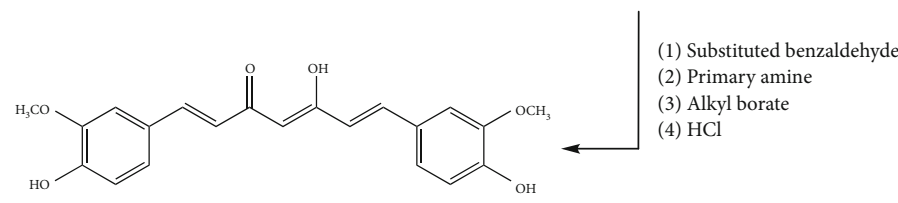

(a)

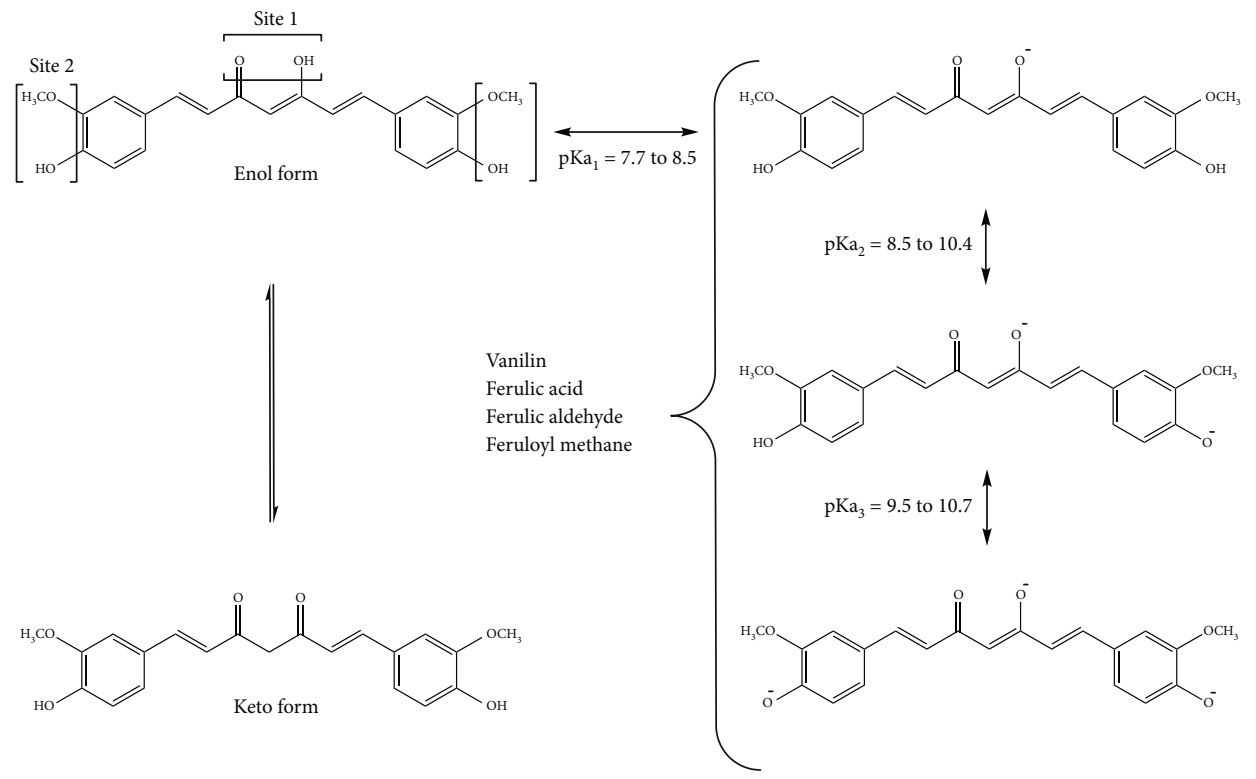

(b)

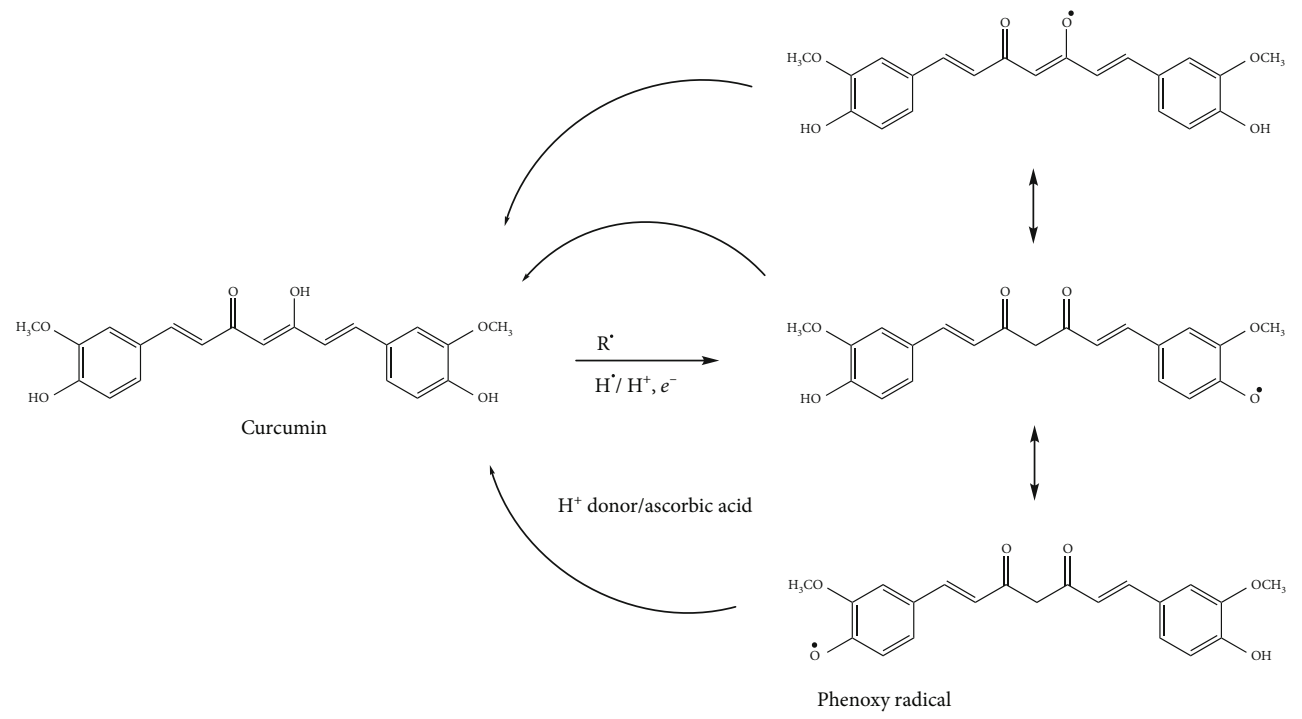

(c)

FIgure 2: General consideration about the curcumin molecule. (a) Synthesis of curcumin by the general method proposed by Pabon [5]. (b) Keto-enol tautomerism (left) prototropic equilibria (right) and some of the degradation products of curcumin (center). (c) Possible sites of attack of reactive oxygen species with stabilization of phenoxyl intermediate and its regeneration by ascorbic acid or other proton donors. Schematic adapted with permission from Priyadarsini [1]. 


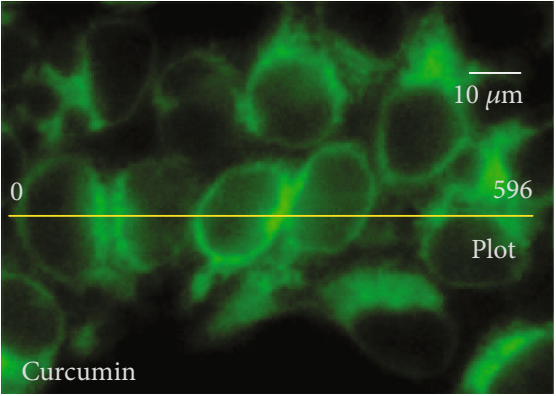

(a)

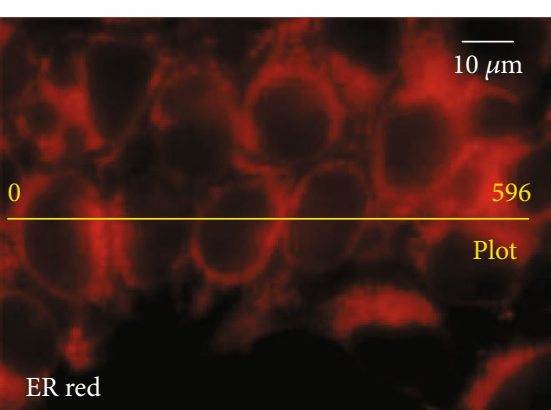

(b)

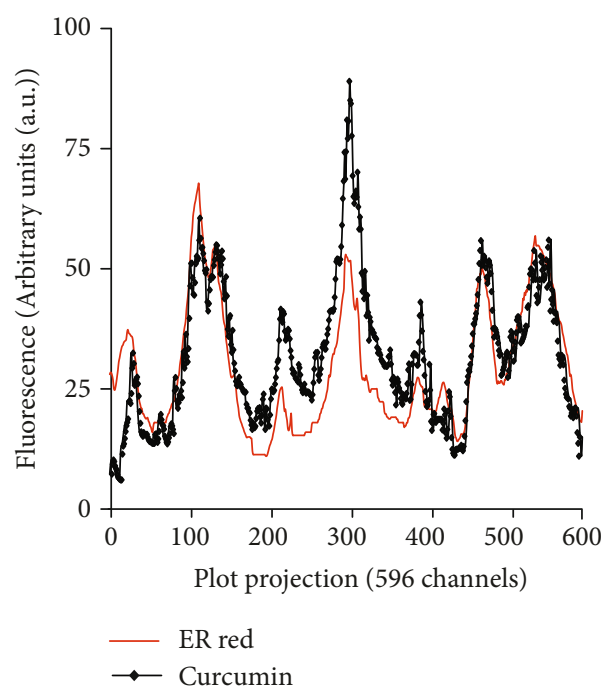

(c)

Figure 3: Curcumin localizes at the endoplasmic reticulum membrane (Patrice X. Petit, personal data and [2, 3]).

The reduction or conjugation of curcumin is thought to be a slow process allowing curcumin to accumulate in cells and exert activity [18]. Glucuronidation of curcumin and curcuminoids, produced by the phase II detoxifying pathway in liver, results in the production of various curcuminoidglucuronides with reduced activity [19]. However, as phase I enzymes are more expressed than phase II, curcumin absorption in liver induces transcriptional responses that enhance the antioxidant capacity of hepatic and extrahepatic tissues, which could explain some of curcumin's chemopreventive properties.

Other properties arise from a possible nucleophilic addition reaction between the unsaturated ketone of curcumin and anions like A-OH, A-SH, and A-SeH from other molecules [13]. As a result, curcumin can bind to various proteins. For instance, conjugation with glutathione-SH results in the depletion of the glutathione pool and the antioxidant defense system (ADS) in cells. In this regard, the depletion of glutathione molecules suggests that curcumin acts as a prooxidant contributor in some conditions [15]. But, depending on the concentration, this stress triggers an adaptive response boosting the glutathione production and other components of ADS. Once a threshold is reached, curcumin drives in parallel endoplasmic reticulum (ER) stress causing calcium release that can result in mitochondrial destabilization, producing more ROS and eventually overcoming the antioxidant defense system (ADS) of cells. This biphasic response is a key feature of an hormetic response discussed previously $[2,3,20]$.

\section{Cellular Uptake and Intracellular Distribution of Curcumin}

Cellular distribution of curcumin has not attracted much attention, even though curcumin fluorescence can be used to localize it within cells, which is of great interest in understanding its mode of action. The effects of curcumin, including the drop in $\Delta \Psi m$ and the production of ROS, do not appear to be the consequences of its direct action on mitochondria [2,3].Indeed, the very early release of calcium into the cytoplasm following curcumin treatment led us to investigate potential interactions between curcumin and ER, which contains the main cellular pool of free calcium. Cellular uptake was observed by confocal microscopy in HuH-7 cells incubated with $20 \mu \mathrm{M}$ curcumin (without $\mathrm{pH}$ indicator) after different time intervals ranging from 0 to 48 hours.As shown in Figure 3, Curcumin fluorescence colocalized with ER red staining [3]. We also evaluated, by $\mathrm{Amnis}^{\circledR}$, curcumin fluorescence with the pattern of lysosome staining assessed with LysoTracker Red DN99 and observed that some lysosomes presented both types of fluorescence, whereas others did not (Figure 4). 


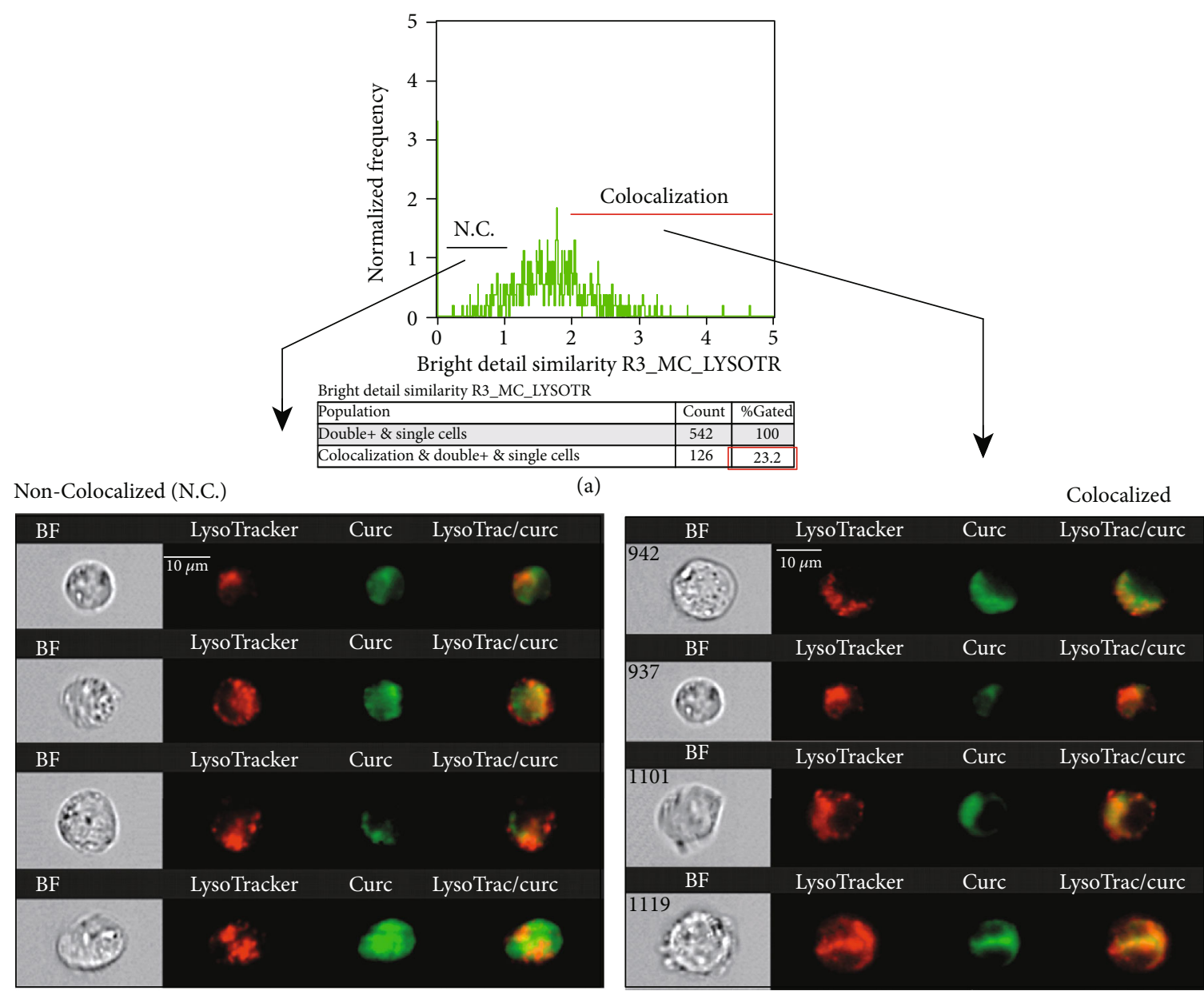

(b)

(c)

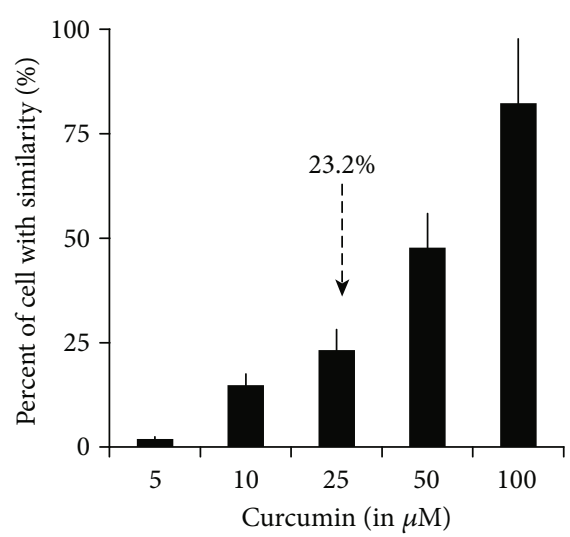

(d)
Mode of calculation of pixel similarity

$$
\begin{aligned}
& \text { Similarity }=\operatorname{In}\left(\frac{1+\rho}{1-\rho}\right) \\
& \rho=\frac{\sum_{i}\left(x_{i}-X\right)\left(y_{i}-Y\right)}{\sqrt{\sum_{i}\left(x_{i}-X\right)^{2} \sum_{j}\left(y_{i}-Y\right)^{2}}}
\end{aligned}
$$

From the AMNIS system

(e)

Figure 4: Lysosomal localization of curcumin as a function of the concentration. (a) Analysis of the colocalization of curcumin and LysoTracker Red (lysosomes) by using the Similarity Score included in IDEAS 6.0 software ${ }^{\mathrm{TM}}$ (Amnis ${ }^{\circledR}$ ). This score, a log-transformed Pearson's correlation coefficient between the pixels of two image pairs, provides a measure of the degree of colocalization by measuring the pixel intensity correlation between the curcumin and LysoTracker images. Analysis was performed on 542 cells. Cells that were permeable to TO-PRO-3 iodide and/or debris were excluded from the analysis together with cellular aggregates. This corresponds to $5 \mu \mathrm{M}$ curcumin and $3 \mathrm{~h}$ incubation plus $10 \mathrm{~min}$ staining at $37^{\circ} \mathrm{C}$ with $100 \mathrm{nM}$ LysoTracker Red. (b) Selection of some images that correspond to cells where there is no strict correlation between curcumin and LysoTracker Red. (c) Selection of some images corresponding to the cells presenting full colocalization of the two probes from the histogram in (a). (d) Percentage of cell population with a similarity index above 2. (e) Equation used for copixelisation analysis. Reproduced from Sala de Oyanguren [3]. 


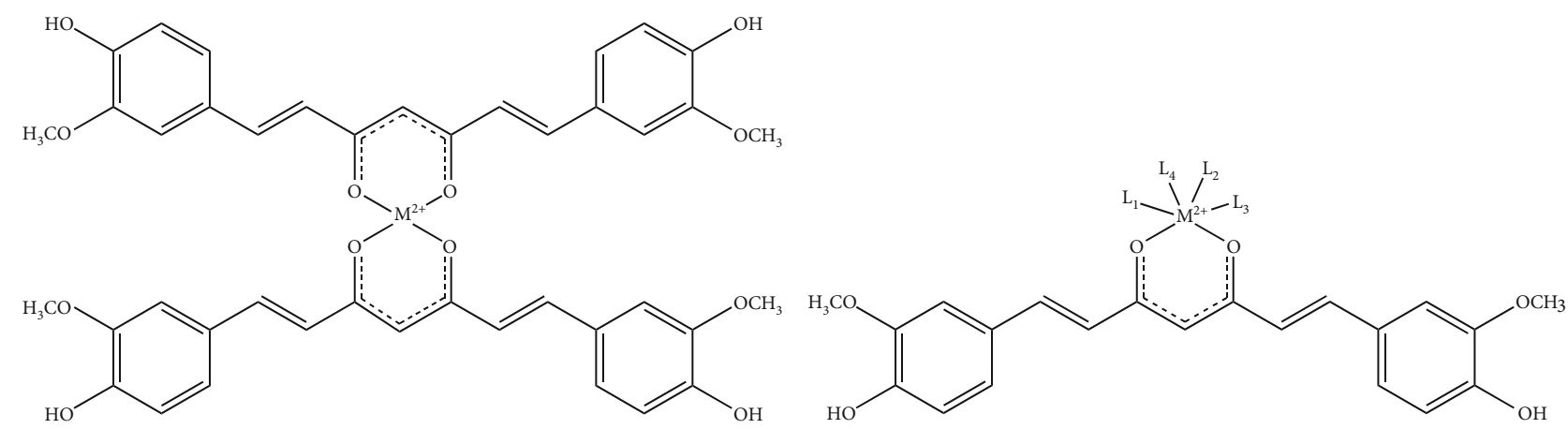

Figure 5: Reaction of curcumin with metals. (a) Structure of a $2: 1$ curcumin: metal complex. (b) Curcumin chelates metals with other ligands. Adapted with permission from Priyadarsini [1].

This suggests that curcumin interactions with lysosomes are strictly dependent on its concentration, a situation that can be explained by an additive pathway which may cooperate with the ER/calcium/mitochondrial pathway previously described $[2,3,21]$.

\section{Curcumin-Metal Complexation Reactions}

The hydrogen bonding and hydrophobicity of curcumin associated with its aromatic ends and tautomeric structures along with the flexibility of the linker are responsible for noncovalent interactions. Curcumin forms strong complexes with most of the known metal ions [1]. The $\alpha, \beta$-unsaturated $\beta$-diketo moiety of curcumin behaves as a chelating agent. Over the last decade, many papers have been published on metal-curcumin complexes, including examples of interactions [18, 19, 22-27] and review papers [1, 23]. Although it is well known that curcumin reduces metal toxicity in living systems through complexation, the actual role of these metal complexes of curcumin in cellular physiology is quite complex and unclear.

More precisely, curcumin can act as a chelating agent (presumably bidentate) for $\mathrm{Fe}^{2+}[28], \mathrm{Fe}^{3+}[29,30]$, and $\mathrm{Cu}^{2+}[14,31]$ (Figure 5). As a chelator of iron, curcumin is supposed to alleviate $\mathrm{H}_{2} \mathrm{O}_{2}$ reduction, which produces hydroxyl radicals $\left(\mathrm{HO}^{\bullet}\right)$ and other ROS [28].

The $\alpha, \beta$-unsaturated $\beta$-diketo moiety of curcumin forms chelates with transition metals, thereby reducing metalinduced toxicity, and some metal complexes exhibit improved antioxidant activity as enzyme mimics. Specific analogs are being developed to improve these activities and have been summarized recently [1, 32, 33].

In this broad literature, most of the promising medicinal applications of metal-curcumin complexes are in the field of anticancer activity with selective cytotoxicity and antineurodegenerative disorders with antioxidative/neuroprotective activity [34-38]. Curcumin-metal complexes not only modify the physicochemical properties of curcumin but also affect the biological reactivity of the metals. From our observations, the proautophagic and proapoptotic activities of curcumin [2,39] are abolished by complexation [20]. Complexation with other metals like $\mathrm{Cu}^{2+}$ and $\mathrm{Mn}^{2+}$ can also reduce their toxicity, and some of the curcumin complexes behave as new antioxidants like superoxide dismutase mimics $[14,15,17,18,31,40,41]$.

In fact, all the metals involved in Alzheimer's disease can form stable complexes with curcumin $[18,19,42]$. For example, curcumin forms three different types of complexes with $\mathrm{Al}^{3+}$, a major suspect in Alzheimer's pathophysiology. In $1: 1$ stoichiometry, the $\mathrm{Al}^{3+}$-curcumin complex has less DNA-binding affinity than free $\mathrm{Al}^{3+}$, which is recognized as a hallmark in reducing the development of $\mathrm{Al}^{3+}$-induced $\mathrm{Alz}$ heimer's disease $[19,42]$. There are many other complexes: $\mathrm{Ga}^{2+}$-curcumin complexes developed as innovative bioceramics [43]; $\mathrm{Zn}^{3+}$-curcumin with anticancer, gastroprotective, and antidepressant effects in rats $[44,45] ; \mathrm{Au}^{2+}$-curcumin (five-coordinated form), which shows antiarthritic activity in vivo [46]; and vanadyl-curcumin $\left(\left[\mathrm{VO}(\mathrm{Cur})_{2}\right]^{2+}\right)$, which has antioxidant and antirheumatic activity [47]. Also, it is evident that curcumin reduces the toxicity of heavy metals like $\mathrm{Hg}^{2+}, \mathrm{Cd}^{2+}$, and $\mathrm{Pb}^{2+}$ through metal coordination, with significant reduction in oxidative stress [25, 48-51].

To our knowledge, curcumin-Fe complexes are unable to induce cell death as curcumin alone does [20]. What is truly interesting is that curcumin-metal complexes may also exhibit hormetic behavior, which extends the range of action of curcumin's biological activity [39].

\section{Curcumin Reactivity with Reactive Oxygen Species}

Curcumin, with its three functional groups-one diketone moiety and two phenolic groups, sustains many reactions like hydrogen donation leading to oxidized curcumin, reversible and irreversible nucleophilic addition, hydrolysis, or enzymatic reactions [32].

Curcumin is an excellent scavenger of most ROS, a feature that partially confers its antioxidant behavior in biological systems (Figure 6). ROS consist of both free radical oxidants and molecular oxidants [29, 52-58].

Free radical oxidants participate in electron transfer reactions and in hydrogen abstraction. All three active sites of curcumin may be oxidized by electron transfer and hydrogen abstraction. All three sites in curcumin can be oxidized, but the easiest abstractable hydrogen is from the phenol group, resulting in the formation of phenoxyl radicals, which are stabilized across the keto-enol structure. The most 


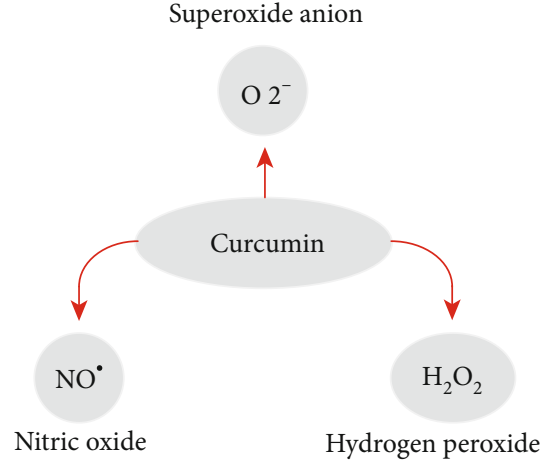

(a)

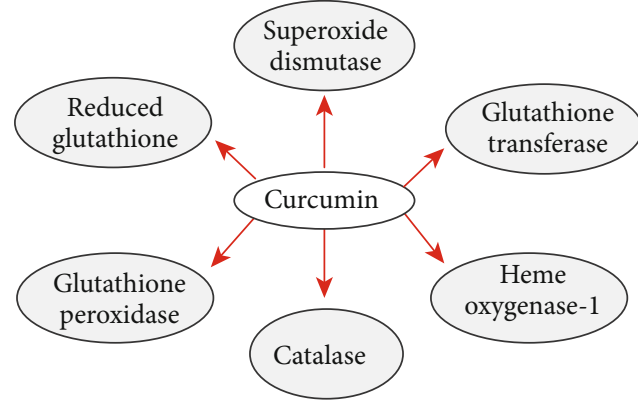

(b)

FIgURE 6: Curcumin antioxidant properties. (a) Curcumin can react directly with ROS. (b) Curcumin upregulates many components of the antioxidant defense system (ADS). Reproduced from Pavan et al. [210].

interesting example is the fact that peroxyl radicals $\left(\mathrm{ROO}^{\circ}\right)$ can react with curcumin and form phenoxyl radicals that are less reactive than peroxyl radicals, thereby enhancing protection against ROS-induced oxidative stress. Soluble antioxidants like ascorbic acid confer upon the molecule a chain-breaking antioxidant capacity like that of vitamin E [53]. Curcumin scavenging of several other free radical ROS such as hydroxyl radicals, superoxide radicals, and alkoxy radicals has been described $[53,55,57,58]$. The reaction of curcumin with superoxide radicals-generally produced at the inner mitochondrial membrane and not diffusible-is as efficient as other antioxidants and leads to catalytic degradation of superoxide in which curcumin acts as a superoxide dismutase mimetic [55].

ROS behavior and function are interestingly bizarre as they are the main regulators in the initiation and regulation of autophagy, cell survival, and cell apoptosis [59]. Despite that antioxidant activity in normal cells and prooxidant activity in cancerous cells have been established, there is still no clear biochemical explanation to this dual function of curcumin [1]. Nevertheless, this selective dual function suggests that curcumin is a potential adjuvant in chemotherapy and radiotherapy protocols to enhance cancer sensitivity and reduce toxicity to normal tissues [60-62].

In cancer cells, curcumin induces ER membrane destabilization, releasing $\mathrm{Ca}^{2+}$, activating downstream signaling proteins such as $\mathrm{C} / \mathrm{EBP}$ homologous protein $(\mathrm{CHOP})$, and upregulating ER transmembrane proteins (PERK, IRE-1 $\alpha$, ATF6) and proapoptotic Bcl-2 protein. These proteins are mediators of ER homeostasis, and excessive accumulation in the ER activates apoptosis $[63,64]$. Over a certain threshold, curcumin induces ER-mediated apoptosis, while lower levels of ROS for the same pathway-under moderate stress like hypoxia-stay in the homeostatic range and allow cancer cells to duck apoptosis [65].

Because cancer cells maintain high levels of ROS-as a consequence of high ROS production or a decline of ROS scavenging capacity-they are selectively vulnerable to further ROS augmentation caused by an exogenous agent like curcumin [66]. Curcumin and new curcumin derivatives at high intracellular concentration $(\geq 2.5 \mu \mathrm{M})$ also behave like proapoptotic agents through mitochondria- dependent mechanisms that induce cell death (mainly apoptosis) in a wide range of cell types [67-71]. Furthermore, curcumin exerts antioxidant effects upon mitochondria via different mechanisms, i.e., decreased production of ROS and upregulation of antioxidant enzymes [72-75].

Enhanced ROS sensitivity of cancer cells could also be attributed to depletion of the reduced thioredoxin (Trx-SH) pool caused by the inhibition of thioredoxin reductase 1 (TrxR1) by curcumin [76]. Indeed, Trx-SH and TRxR1 are key mediators in the maintenance of redox homeostasis of cells by maintaining a defense pool against oxidation [77].

\section{Curcumin at the Crossroads between Autophagy, Necroptosis, and Apoptosis}

In the following sections, we will try to depict the mechanistic aspects of curcumin-induced autophagy and apoptosis separately, occurring in the general context of a complex intracellular machinery dysregulation. This approach is somewhat absurd, but will facilitate the depiction of parallel signaling pathways all of which have their own thresholds regarding mitochondrial life, autophagy, cell cycle arrest, and cell death.

5.1. Curcumin, Autophagy, and Cell Death. Autophagy is the degradation process of supernumerary or dysfunctional components within cells. Any targeted cytosolic materials or organelles are ultimately delivered and recycled in lysosomes thus functioning as an important biological mechanism for cell homeostasis. As autophagy is such an ubiquitous and fundamental mechanism for the cell, autophagy dysfunction can be found in a number of diseases even if molecular evidences are still needed [78]. Autophagy in cancer diseases has attracted much attention to modulate cell death when targeted by therapeutic candidates like curcumin.

With the discovery and characterization of Atg proteins, the suppressive function of autophagy in cancer has been validated $[79,80]$. Among the Atg genes, beclin 1 (Atg6) is an essential tumor suppressor that modulates the initiation and regulation of autophagy. BECN1 gene deletion is often present in human breast, ovarian, and prostate cancers, and aging $B e c n 1^{+/-}$mice are prone to tumors including lymphomas 
and lung and liver cancers [81-83]. The accumulation of autophagosomes in dying cells is correlated with autophagic cell death, also defined as a nonapoptotic form of programmed cell death (PCD) or type II PCD with a potential function of tumor suppression similar to apoptosis.

In addition to its tumor suppressive role, autophagy is involved in cancer cell survival under stress. For example, immortalized, apoptosis-defective, IL-3-dependent bone marrow cells deprived of growth factor show a better survival response when autophagy is induced. Accordingly, autophagy inhibition accelerates cell death $[84,85]$. Other stressors like hormonal deprivation, chemotherapy, and radiation-in many cases - upregulate autophagy as a cell survival mechanism [86]. As this upregulation can be cell specific and modulates cell fate in a tissue, it may contribute to treatment resistance. In tumors, inflammation and lack of vasculature may often result in a decrease of glucose and oxygen levels. This perturbation in the tumor microenvironment, as well as acidosis, can induce autophagy. Autophagy is therefore a functional driver and a marker of cancer severity in clinical research $[86,87]$.

In this context, the anticancer activity of curcumin can be investigated. Curcumin acts also both as a tumor suppressor and cancer cell protector [86-89].

The injection of curcumin in mice bearing breast cancer produces a clear inhibitory effect on the growth of breast cancer cells and metastasis [90].

Curcumin can inhibit the proliferation of tumor cells (Table 1) and induce the apoptosis of tumor cells (Figure 7), including bladder cancer [91], pancreatic cancer [92], prostate cancer [93], and uterine cervix carcinoma [94]. Curcumin also enhances the sensitivity to thermotherapy and $\gamma$-ray therapy $[95,96]$.

In vitro, curcumin inhibits cell proliferation of chronic granulocyte leukemia (CGL), glioblastoma, and esophageal cancer through autophagy induction, by upregulating LC3II and beclin 1, as well as accumulating autophagosomes. In contrast, with the autophagy inhibitor bafilomycin A1, curcumin-induced cell death is inhibited [97].

Curcumin can inhibit both PP1 and the Akt/p70S6K pathway to activate extracellular signal-regulated kinases (ERK1/2) and finally induce autophagy [98]. Besides activating autophagy, curcumin also exhibits time- or concentrationdependent inhibition of the growth of K562 cells.

Cell death induced by curcumin is correlated with the generation of autophagosomes, a drop of mitochondrial potential, and caspase activation [2, 3, 39]. In addition, curcumin reduces the expression of Bcl-2 protein in K562 cells [99]. A combined treatment of curcumin and adriamycin enhances the apoptosis of HepG2 cells by reducing the proportion of Bcl-2/Bax protein and caspase-3 activation, in parallel with an increase in autophagic flux and mitochondrial fission. These data may indicate that curcumin can increase adriamycin-induced toxicity by activating mitochondriamediated autophagy [100].

5.2. Curcumin, ER-Mitochondria, and Apoptosis. The initial effects of curcumin could be due to its interaction with subcellular compartments since, as a lipophilic polyphenol, it
TABLE 1: Antiproliferative target for curcumin.

\begin{tabular}{llll}
\hline Target & Effect & Cancer type & Refs. \\
\hline GRP78 & Downregulation & Colon & {$[211]$} \\
EphA2 & Downregulation & Melanoma & {$[212]$} \\
SOCS1 and 3 & Upregulation & Leukemia & {$[213]$} \\
Nfr2 & Downregulation & Breast & {$[214]$} \\
MiR15a/16-1 & Downregulation & Leukemia & {$[215]$} \\
DCLE1 & Upregulation & Colon & {$[216]$} \\
Skp2 & Downregulation & Glioma & {$[217]$} \\
FOXO1 & Upregulation & Pancreas & {$[218]$} \\
EZH2 & Downregulation & Breast & {$[219]$} \\
\hline
\end{tabular}

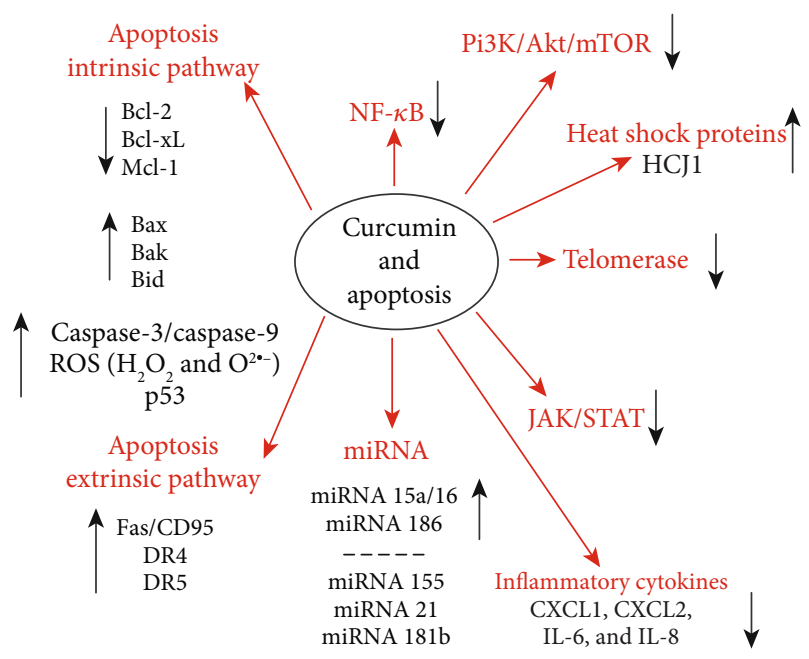

FIgURE 7: Schematic interpretation of the effects of curcumin on apoptosis. Representation is modified from Pavan et al. [138], redrawn, and completed. In red are the main pathways and proteins affected. In black, indirect interaction or tissue-dependent pathways.

could be associated with total lipophilic load and membranes. These subcellular compartments are essentially ER and the lysosomes [2, 3, 39], since oxidative stress [101-104], lipid peroxidation [105], and calcium increase $[106,107]$ are associated with curcumin treatments and all these events are involved in the induction of cell death $[102,108]$ or specifically apoptosis [109-111]. A plethora of recent papers brought evidence of curcumin binding to and/or inhibiting numerous proteins, i.e., $\mathrm{Nrf} 2, \beta$-catenin, NF- $\kappa \mathrm{B}$, inducible nitric oxide synthase, nitric oxide, amyloid plaques, ROS, cyclin D1, glutathione, cytosolic phospholipase A2, inhibitor of NF- $\kappa$ B kinase-1-2, $\mathrm{P}_{38} \mathrm{MAPK}$, p-Tau $(\mathrm{p}-\tau)$, and TNF $\alpha$.

Most of the mechanisms by which curcumin exerts its anticancer effect have been reported to be related to cell death induction. Curcumin inhibits the inhibitor of $\kappa \mathrm{B}$ kinase and I $\kappa \mathrm{B} \alpha$ phosphorylation [112-115].

So, curcumin downregulates all genes downstream of NF- $\kappa$ B such as Bcl-2, Bcl-XL, cyclin D1, cyclin B1, matrix metalloproteinase-9, cyclooxygenase-2, and interleukin-6, resulting in cell cycle arrest (G2/M) (Figure 8 ) and induction 


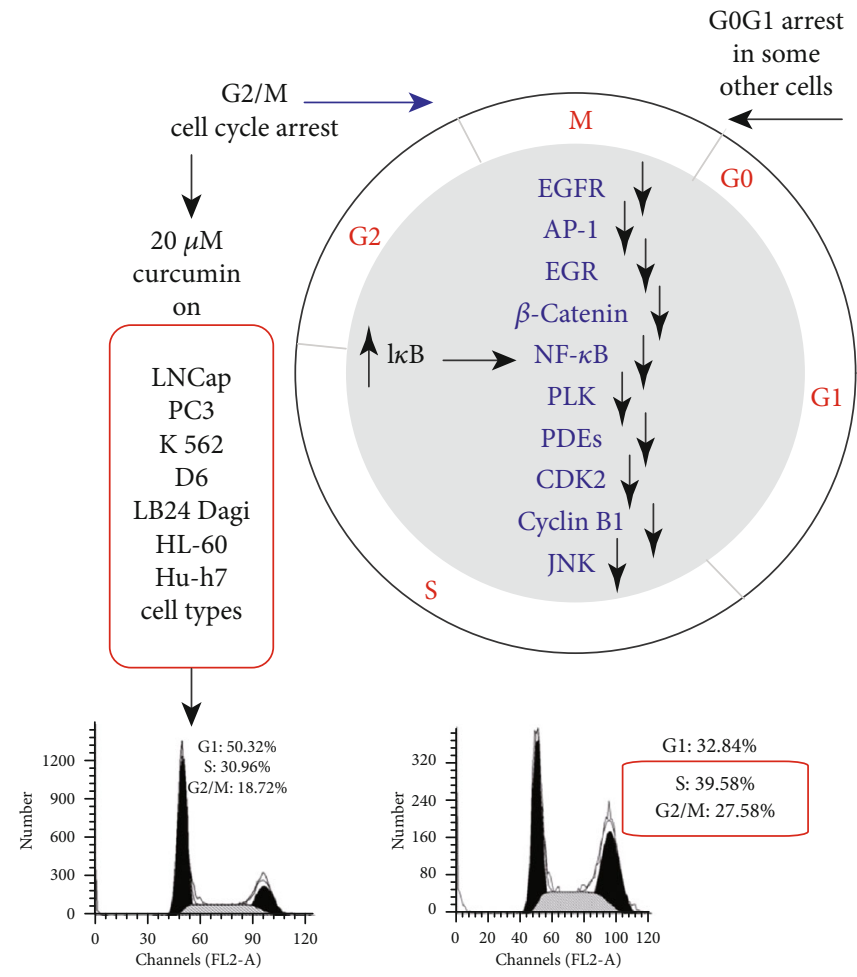

FIGURE 8: Schematic interpretation of curcumin interaction with partners involved in cell cycle and validation of these effects of G2/M blockade on many cell lines.

of apoptosis [64, 112, 115-117]. Also, curcumin exerts a strong inhibition resulting in a decreased cellular proliferation and induction of apoptosis that is mediated via the blockage of the Akt/mammalian target of rapamycin (mTOR) pathway and the phosphorylation of p70 ribosomal protein S6 kinase (p70S6K) and eukaryotic initiation factor 4 E-binding protein $[64,118-120]$. Among the antitumor effects of curcumin are the downregulation of the transcription factors activator protein-1 [121-125] and Egr-1 (Figure 8). Curcumin very potently reduces the cellular entry of viruses [126] and suppresses phorbol-esterinduced tumor promotion [127]. As curcumin can enter intracellular membranes and modify permeability and fluidity, it also acts on transporters and ion channels [128, 129]. Curcumin in association with the TORC1 and 2 inhibitors is thought to induce apoptosis via lysosome membrane permeabilization-associated autophagy [130].

-The curcumin capacity to induce an hormetic response is characterized by the numerous targets driving - depending on the dose - both antioxidant and prooxidant properties that can be related to the autophagic and cell death processes. The molecular circuits that link curcumin to cellular stress and death and how these pathways are uncoupled during hormetic responses are subjects of great interest $[2,3,39]$. Curcumin at very low concentrations $(\leq 1 \mu \mathrm{M})$ behaves as an excellent antioxidant, but higher concentrations of curcumin $(5-10 \mu \mathrm{M})$ operate primarily as an autophagy inducer, correlated with their capacity to reduce the acetylation of cytoplasmic proteins and cell cycle blockers (Figure 8).
Finally, at even higher concentrations-over $25 \mu \mathrm{M}$-autophagy fails to rescue cells and cell death is induced. We investigated the mechanistic aspects of the destabilization of ER and lysosomes involved in mitochondrially associated apoptosis. Curcumin induces an ER stress causing calcium release that in turn destabilizes the mitochondrial compartment to induce apoptosis. These events are also associated with lysosomal membrane permeabilization and activation of caspase-8, mediated by the activation of cathepsins and calpains [2,3]. This complex interplay is of huge interest, as efficient autophagy may allow cells to escape the G2/M blockade [2] induced by curcumin when used at around 10-20 $\mu \mathrm{M}$ in the extracellular medium [3] (Figure 8).

5.3. Curcumin, Lysosomes, and Autophagy. As mentioned before, under physiological conditions, basal autophagy is a catabolic process where lysosomes are mainly involved in the degradation of damaged components and dysfunctional organelles in cells. Autophagy has attracted the interest of scientists in the field of cancer research because it is designated as an alternative programmed cell death (type II), whereas apoptosis is well known as programmed cell death type I [131]. But this definition has been modified and adapted to the discovery of multiple cell death pathways and of a diversity of autophagic processes.

We previously showed that a fraction of internalized curcumin is bound to the lysosomal membranes [2, 3] (Figure 4). Lysosomal destabilization by curcumin is critically dependent on the intracellular curcumin concentration; the occurrence of soluble lysosomal hydrolases, i.e., 
cathepsins and chemotrypsins; and the dysfunction of lysosomal-associated membrane proteins (LAMPs).

Growing evidence argues for the presence of highly activated PI3K/Akt signaling in cancer cells compared to normal ones. As we said earlier, curcumin inhibits the Akt-mTOR pathway and interferes with PI3K/Akt signaling, leading to the inhibition of the proliferation and reduction of the invasiveness and migration of various cancer cells, including triple-negative cancer cells [132-135].

The Akt $/ \mathrm{mTOR} / \mathrm{p} 70$ ribosomal protein S6 kinase (p70S6K) and the extracellular signal-regulated kinase $1 / 2$ (ERK1/2) pathways are two major pathways that regulate autophagy induced during nutrient starvation. The Akt $/ \mathrm{m}$ TOR/p70 and ERK1/2 pathways are frequently associated with oncogenesis in a variety of cancer cell types, including malignant gliomas. In U87-MG and U373-MG malignant glioma cells, curcumin induces G2/M arrest (Figure 8) and nonapoptotic autophagic cell death. It inhibits the Akt $/ \mathrm{m}$ TOR/p70S6K pathway and activates the ERK1/2 pathway, thus inducing autophagy. It is interesting that the activation of the Akt pathway inhibits curcumin-induced autophagy and overall cytotoxicity, whereas the inhibition of the ERK1/2 pathway inhibits curcumin-induced autophagy and induces apoptosis, thus resulting in enhanced cytotoxicity. These results suggest that curcumin has high anticancer efficacy in vitro and in vivo by inducing autophagy [98].

Nevertheless, the effect of curcumin on lysosomes remains largely elusive. Some recent data suggest that currently known transcription factor EB (TFEB) activators are mainly inhibitors of mTOR which, as a master regulator of cell growth and metabolism, is involved in a wide range of biological functions [132-137] and exerts its effect at the lysosomal membrane surface [137].

It has also been suggested that curcumin treatment may activate TFEB [138]. TFEB is a major player of the transcriptional response to starvation and controls autophagy by inducing lysosomal biogenesis, regulating autophagosome formation and autophagosome-lysosome fusion both in vitro and in vivo [139]. This is based on the cardinal hypothesis that a lysosome-to-nucleus signaling mechanism senses and regulates the lysosome via TFEB and mTOR [140]. Linked to lysosomal membranes, TFEB colocalizes with the master growth regulator mTOR complex 1 (mTORC1). The arguments for the fundamental role of TFEB are the following: curcumin binds directly to TFEB (and/or disturbs the membrane in the vicinity of TFEB insertion), promotes TFEB nuclear translocation, and increases the transcriptional activity of TFEB. TFEB modulators that act without inhibiting the mTOR pathway would probably be less deleterious to cells [141]. Along with this new argument, it has been reported that curcumin does not inhibit mTOR and fails to activate lysosomal function when constitutive activation of mTOR has been engineered, proving that curcumin-mediated lysosomal activation is achieved via suppression of mTOR activity. The AMPK-JNK pathway can also be activated by curcumin, which drives both mTOR inhibition and Bcl-2 upregulation and in turn enhanced autophagy and suppressed apoptosis [142]. Finally, inhibition of autophagic fluxes and activation/destabilization of the lysosomal compartment by curcumin, if passing a certain threshold, lead to more cell death, suggesting that lysosomal activation and enhanced autophagy serve-if successfully executed-as a cell survival mechanism to protect against curcumin-mediated cell death.

Taken together, all these data built up a novel insight into the regulatory mechanisms of curcumin at the lysosomal level (enhancing autophagy), which may reinforce the relevance of curcumin as a potential cancer therapeutic agent [138], but may also be used for lysosomal storage disorders, neurodegenerative disorders, and cardiovascular diseases.

\section{Curcumin and Mitochondrial Turnover}

6.1. Mitochondrial Biogenesis. Mitochondria are the key compartments of cellular energy metabolism that is also fundamental for apoptosis regulation and cell signaling. It is now established that the mitochondria of malignant cells differ structurally and functionally from those in normal cells and are mainly characterized by ROS overproduction, which may promote genomic instability by the alteration of gene expression and the modulation of signaling pathways. Both oxidative damages targeting the mitochondrial compartment and nuclear DNA induce further alterations of oxidative phosphorylation and enhance mitochondrial-specific ROS production, sustaining a "vicious cycle" between mitochondrial ROS, genomic instability, and cancer development. Alternatively, an impaired oxidative phosphorylation or mitochondrial biogenesis is found in neurodegenerative diseases [143-145], cardiovascular diseases [146], and type II diabetes [147].

In this context, mitochondrial biogenesis-taken as the increase of the mitochondrial network-is a complex response to various stimuli that relies on both mitochondrial and nuclear genomes. Usually stimulated under supraenergetic demand, mitochondrial biogenesis involves a master regulator called peroxisome proliferator-activated receptor $\gamma$ coactivator $1-\alpha$ (PGC- $1 \alpha$ ) with peroxisome proliferatoractivated receptor alpha (PPAR $\alpha$ ) activating nuclear respiratory factors 1 and 2 (NRF1/NRF2) among others [148]. Metabolic sensors like AMP-activated protein kinase (AMPK), $\mathrm{NAD}^{+} / \mathrm{NADH}^{\prime} \mathrm{H}^{+}$ratio, or ROS levels are first players of the PGC- $1 \alpha$ pathway [149]. AMPK can modulate NAD ${ }^{+}$levels in the cell contributing to [150] the activation of a $\mathrm{NAD}^{+}$dependent deacetylase sirtuin 1 (SIRT1), which activates PGC- $1 \alpha$ through deacetylation [151-153]. Accordingly, high PGC- $1 \alpha$ levels are found in tissues with high rates of oxidative phosphorylation, facing high ATP needs [154-156]. Once activated, the AMPK/SIRT1/PGC- $1 \alpha$ pathway involves NRF1 and NRF2 activating downstream of the estrogenrelated receptor $\alpha(\mathrm{ERR} \alpha)$ and the expression of mitochondrial transcription factor A (TFAM) and transcription factors B1 and B2 (TFB1M and TFB2M) [157-163]. These transcription factors are responsible for both the increased expression of nuclear DNA encoding for mitochondrial proteins [164] and the transcription/replication of mitochondrial DNA (mtDNA) [165-167], thereby orchestrating mtDNA homeostasis at large $[165,168,169]$. 


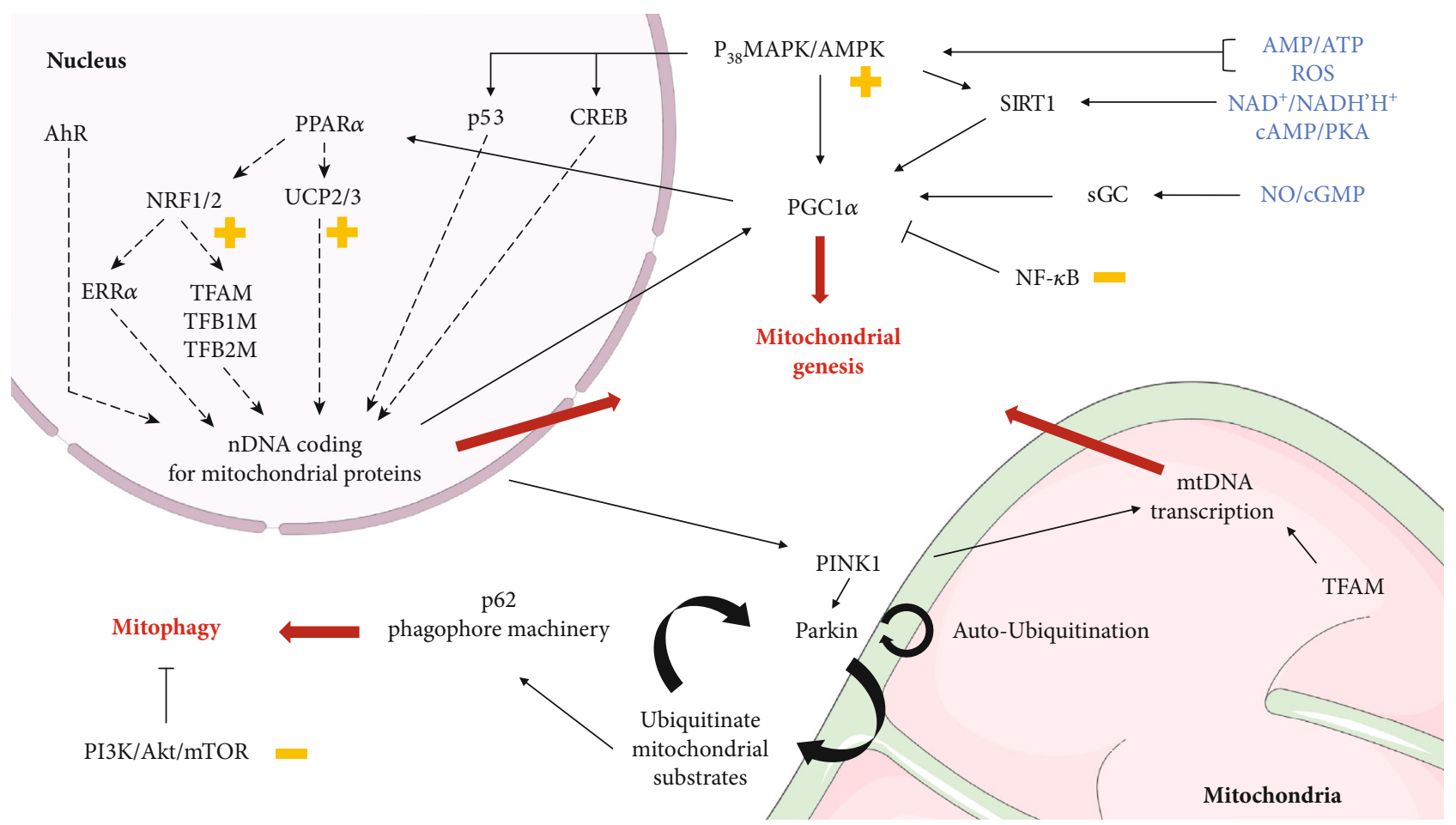

FIGURE 9: Mitochondrial turnover highlights with curcumin regulations. Various energetic and redox sensors (in blue) can activate the master regulator PGC- $1 \alpha$ stimulating mitochondrial biogenesis mainly by upregulating transcription of numerous mitochondrial proteins. Plus and minus yellow signs indicate curcumin regulations. Nonselective mitophagy can be activated by various pathways like mTORC1, but selective mitophagy is initiated by depolarized mitochondria. Loss of mitochondrial membrane potential is followed by PINK1 accumulation at the surface which phosphorylates PARKIN. Active PARKIN further promotes its recruitment and phosphorylation by PINK1 in a feedforward mechanism. These ubiquitinated substrates can activate p62 and the autophagy machinery to perform mitophagy. Some graphic elements are adapted from Servier Medical Art (CC-BY 3.0).

In this context, the AMPK/SIRT1/PGC- $1 \alpha$ pathway orchestrates mitochondrial biogenesis and participates in redox homeostasis, crucial for cell life (Figure 9).

Studies describing curcumin as an enhancer of mitochondrial biogenesis are quite recent and should point to a new path for curcumin studies, as a kick-start to develop newly designed drugs that target dysfunctional mitochondria found in cardiovascular diseases and neurodegeneration.

However, the external concentrations of curcumin used in experimental models discussed here are high and may not be reached in the human system through food or oral medication. As mentioned before $[2,3]$, it will be necessary to improve curcumin bioavailability, to ensure that higher curcumin concentrations can be reached, or to find a way to address curcumin to target cells. This explains why curcumin is becoming a common model in biotechnology and drug delivery studies seeking better permeability and stability [170] as well as new nanoformulations [170-172].

In vitro, curcumin has been described as a potent inducer of a brown fat-like phenotype in 3T3-L1 and primary white adipocytes [173].

In these cells, $20 \mu \mathrm{M}$ curcumin for 6 days upregulates PGC- $1 \alpha$, associated with an increased level of cytochrome $c$, the phosphorylated form of AMPK (p-AMPK), Nrf1, TFAM1, and the total mtDNA transcript.
In gentamicin-treated LLC-PK1 cells, $30 \mu \mathrm{M}$ of curcumin for $24 \mathrm{~h}$ induces Nrf2 translocation and upregulates PGC- $1 \alpha$. This evidence shows that curcumin can elicit mitochondrial biogenesis in vitro via Nrf2 as a master regulator of the redox cellular environment $[174,175]$.

More in vivo studies are in line with these data and show that curcumin can upregulate respiratory chain components. In gastrocnemius and soleus muscles of rats submitted to long-lasting exercise training, curcumin induces an increase in the amounts of cytochrome $c$ oxidase and various subunits of complexes I, II, and III [176]. Curcumin also stimulates the effects of exercise training upon mtDNA synthesis and citrate synthase (CS) activity which are the gold standards for evaluating mitochondrial biogenesis in muscles. As curcumin can modulate $\mathrm{AMP}$ and $\mathrm{NAD}^{+}$levels, it can thereby activate $\mathrm{AMPK}$ and all downstream players of the AMPK/SIRT1/PGC- $1 \alpha$. Rats submitted to ischemic reperfusion injury after curcumin pretreatment exhibited a better developed mitochondrial network in the cerebral cortex [177]. Curcumin pretreatment prevented the injury-induced downregulation of uncoupling protein 2 (UCP2),Nrf1 levels. and TFAM which were upregulated at all concentrations tested. Curcumin $\left(400 \mathrm{mg} / \mathrm{kg} \mathrm{day}^{-1}\right)$ provided by gavage prior to gentamicin (a renal toxin) exposure preserved mitochondrial morphology and enhanced the number of mitochondria [175]. 
In mice, curcumin also demonstrated the browning of white adipose tissue by UCP 1 and PGC- $1 \alpha$ upregulation, with an increase of mtDNA transcripts [178].

All these findings reinforce the new hypothesis that curcumin at very low concentrations may induce mitochondrial biogenesis, but new data on the impact of curcumin on regulators of mitochondrial biogenesis, such as AMPK, SIRT1, NRF1, and TFAM, will be of great interest.

6.2. Curcumin and Mitophagy. It is now established that a fine regulation balancing mitochondrial biogenesis and mitophagy is essential to maintain the adaptability of the cell to its metabolic state, intracellular stress, and environmental signals [179].

Regulatory factors contributing to mitochondrial homeostasis have also been linked to carcinogenesis, which points at mitophagy as a potential target for cancer therapy [180].

Mitophagy is the process by which damaged mitochondria are removed from the cells through engulfment by an active autophagosome in a PTEN-induced kinase 1 (PINK1)/Parkin (E3 ubiquitin ligase)-dependent mechanism [181-183]. Despite being a physiological process, increased rates of mitophagy have been found in some human diseases and may represent a major risk for redox and bioenergetic homeostasis [184-187].

The capacity of curcumin to induce mitochondrial biogenesis (certainly at low concentrations) in response to enhanced energetic demand is followed by curcumin's potential to trigger mitophagy $[2,3,188]$, and once again the threshold concept is of most relevance.

CNE2 cells (nasopharyngeal carcinoma) can be sensitized with $10 \mu \mathrm{M}$ curcumin before being exposed to ultrasound [189]. A combination of ultrasound and curcumin increases the number of swollen mitochondria and impairs mitochondrial membrane architecture. These results constitute some evidence that altered mitochondria could be eliminated by specific autophagy in response to curcumin. Nevertheless, more data are needed to elucidate if curcumin is a general inducer of autophagy or contributes specifically to a mitophagic process.

Additional data are needed to elucidate the exact role of curcumin as an inducer of mitophagy. The scenario in which curcumin would be useful in inducing mitochondrial degradation requires more detail.

\section{Curcumin and Regulatory MicroRNA}

In cancer research, microRNAs (miRs) have attracted much attention as one therapeutic agent could physiologically regulate multiple targets to limit cancer progression. However, as multiple pathways are involved with hundreds of miRs, this approach is still challenging. Recent studies revealed that curcumin can regulate miRs, and one strategy may be to investigate miRs through curcumin multitargeting.

MicroRNA-21 (miR-21) can be taken as a model for studying regulatory mechanisms between microRNA and curcumin [190, 191]. miR-21 is involved in proliferation, apoptosis, metastasis, and anticancer drug resistance. miR21 is also involved in several downstream pathways, such as phosphatase and tensin homolog (PTEN), phosphoinositide 3-kinase, protein kinase B (PI3K/Akt), programmed cell death protein 4 (PCD4), and MAPK pathways, and in the enhancement of p53 and NF- $\kappa \mathrm{B}$ pathways. It is interesting to note that all these pathways have been described as being affected by curcumin cellular loading. Curcumin decreases miR-21 levels by both increasing the miR-21 exosome outside the cells and by binding to its promoter, a situation that decreases the transcription of the miR-21 gene.

Beyond miR-21 inhibition, curcumin induces epigenetic alterations by modulating the expression of several other oncogenic and tumor suppressor miRs (Table 2). Suppression of oncomiRs such as miR-21, miR-17-5p, miR-20a, miR-27a, and miR-186* [191] and overexpression of miR34 and epithelial-mesenchymal-transition suppressor miRs are among the most important effects of curcumin [192]. A recent publication highlights curcumin as a relevant miR regulator for cancer progression and points out that exosomes produced in curcumin-treated cells contain both miRs and curcumin and carry anticancer properties for the recipient cells [193]. This mechanism of physiological vectorization of curcumin, by curcumin or not, may open a new approach to investigate for potential therapeutic tools in cancer therapy.

\section{Curcumin: PAINS or Nutraceutical?}

As previously discussed, curcumin has been attracting massive attention, particularly over the last decade, not only for its use as a chemotherapeutic agent but also for its antioxidant properties. It has several advertising advantages: a natural product already used in Ayurvedic medicine, easily extractible from plants (turmeric), rather inexpensive, and with beneficial effects when included in the diet, the latter observation being initially supported by epidemiological studies. Its pleiotropic effects as evidenced in numerous studies attracted the attention of scientists and lay people drawn to natural products now labeled as "superfoods."

On the other hand, some researchers raised concerns about curcumin and other natural products classifying them as Pan Assay Interference Compounds (PAINS) [194].

Typically, it does not behave in a drug-like manner with its target, a behavior potentially unspecific, unquantifiable, and interfering with assays measuring them or other readouts. Warnings come from the drug discovery field, in highthroughput screening (HTS) where these PAINS largely return as "hits" for a considered target. Of course, anyone actively involved in high-throughput screening (HTS) should consider the latest considerations regarding PAINS to filter their hits [195]. In fact, HTS experts working with biologists know that it is considered a rather uncertain research often leading to multiple "hits", hitting themselves multiple targets [196].

Medicinal chemists warned us about curcumin's status not only as a PAINS but also as an AIC (assay interference compound) and an IMP (invalid/improbable metabolic panacea) status) [197] which has led to divisions within the scientific community [198, 199]. The complexity of curcumin's behavior should reinforce our interest to discuss the best way to design our tests and readouts. In this review, we point out the hormetic behavior of curcumin and its ability to hit multiple pathways, and not only proteins but also 
TABLE 2: Curcumin alters miRNAs and relevant target expression in pancreatic, colorectal, breast, and lung cancers.

\begin{tabular}{|c|c|c|c|c|}
\hline Cancer origin & Upregulated & Downregulated & Targets & Refs. \\
\hline \multirow{2}{*}{ Pancreas } & miR-22 & $\operatorname{miR}-21$ & SP1, ESR1 & {$[220]$} \\
\hline & $\operatorname{miR}-200$ & miR-199a* & PTEN & {$[221]$} \\
\hline Colorectum & - & $\operatorname{miR}-21$ & AP1, Pdcd 4 & {$[222]$} \\
\hline \multirow[t]{2}{*}{ Breast } & miR-15a & - & Bcl-2 & [223] \\
\hline & miR-16 & - & & \\
\hline Lung & mir-206 & - & $\mathrm{PI} 3 \mathrm{~K} / \mathrm{AKT} / \mathrm{mTOR}$ & {$[224]$} \\
\hline Lung & $\operatorname{miR}-186^{*}$ & - & Caspase-10 & {$[191]$} \\
\hline Retinoblastome & - & miR-99a & JAK/STAT & {$[225]$} \\
\hline Thymic carcinoma & & miR-27a & Notch $1 /$ mTOR & [226] \\
\hline Osteosarcoma & - & miR-21 & RECK & {$[227]$} \\
\hline Retinoblastome & miR-22 & - & Erbb3 & [228] \\
\hline
\end{tabular}

*Additionally, curcumin regulates many other miRNA expressions, e.g., miR-1, miR-7, miR-9, miR-19, miR-34a, and miR-181 [193].

membranes. What could be a "no go" to researchers following the perspective of one drug and one protein with one active site can be put in perspective of the advantages of modulating a balance of pathways and doing some, what researchers call, multitargeting [200].

To circumvent some of the limitations of natural products like poor solubility and bioavailability, researchers vectorize them with nanomaterials. A literature search will show that curcumin and nanoparticles return hundreds of studies, and more than half of them have applications for cancer; the rest are comprised of applications for inflammation and vascular diseases.

It would need a complete separate review to cover curcumin and its nanoformulations, but the therapeutic use of natural products could benefit from research in nanomedicine as some of the latest nanoformulations are using targeting moieties that are tissue- and cell-specific [201, 202]. Such nanoformulations could alleviate most of the systemic limitations of curcumin and bring that "multitargeting drug" at the cellular level.

\section{Conclusion}

Although some fourteen thousand publications contain the term curcumin, few studies have followed new research directions. It is clear that low levels of curcumin enhance mitochondrial biogenesis in cells and tissues, mainly through the induction of the PGC- $1 \alpha$-related signaling pathway [203, 204]. The exact mechanism of curcumin-induced mitochondrial biogenesis is incompletely understood, since the roles of AMPK, NRF1, Nfr2, and/or TFAM that are essential in biological processes were not investigated in most published studies. It is sure that TFEB is also involved in such pathway, participating in lysosomal biogenesis together with autophagy induction [138]. Molecules such as PGC- $1 \alpha$ are thought to be critical for the maintenance of organelle content. The hypothesis that the induction of mitochondrial biogenesis by exogenous polyphenols may play a role in alleviating cellular dysfunction with the disruption of mitochondrial bioenergetics, in cases of neurodegenerative and cardiovascular diseases, is of great value, even though our knowledge of curcumin-mediated regulation of mitochondrial biogenesis is limited $[165,166,168]$.

Investigations of the role of curcumin as an inducer of mitochondrial biogenesis and mitophagy in a context of mitochondrial energetic disturbance are in their infancy. By focusing efforts on TFEB, a protein widely considered to be the most important regulator of autophagy and lysosomal biogenesis, we may perhaps shed light on the regulation of mitophagy in various cell types.

Curcumin induces crosstalk between apoptosis and autophagy and is thought to interact with proteins that belong to both pathways and are involved in the regulation of cancer cell death. Most researchers consider that cancer progression is in large part due to defects in cell death mechanisms [205, 206]. These defects shield tumor cells from drugs and therapies, thus prolonging cell life and promoting cell dispersion. Autophagy and apoptosis are safeguards against cellular damages and uncontrolled outgrowth and differentiation of harmful cells. Autophagic proteins generally hinder apoptosis, whereas apoptotic intermediates prevent autophagic responses. Additionally, curcumin analogs have been described with attenuating properties on $\mathrm{AD}$ accumulation in a mouse model of Alzheimer's disease [207]. This effect is mediated by a reduced level of amyloid- $\beta$ protein associated with enhanced autophagy.

The case of curcumin, autophagy, and apoptosis, which are highly intricate pathways (Figure 10), can be investigated by manipulating their mutual proteins. Targeting these shared proteins involved in the crosstalk between autophagy and apoptosis so as to regulate tumor cell death is crucial for the successful design of future anticancer therapies. MicroRNAs are involved in the modulation of these components that interact in both autophagy and apoptosis in cancer cells. Since the development of miRNA-based therapeutics seems to be hazardous and time-consuming, additional approaches need to be considered. Curcumin as a phytochemical may fill this gap since it has been reported to switch these interplaying proteins to maximize cancer cell death through the partnership of autophagy and apoptosis [2, 39, 138]. This may enable us to chart the missing links between these machinery proteins, organelle membranes, and miRNAs. 


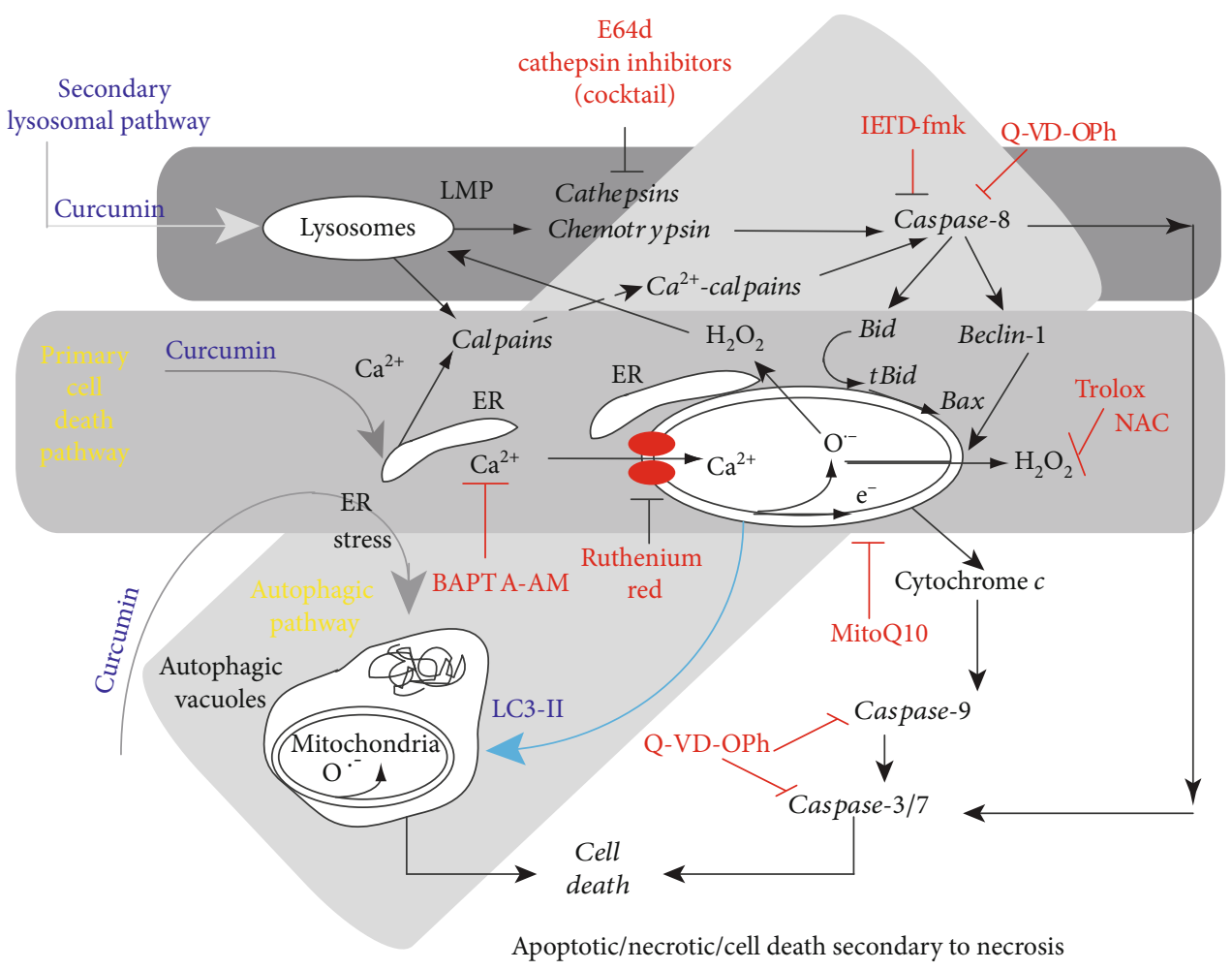

FIGURE 10: Crosstalk between apoptosis and autophagy in cells treated with curcumin. Curcumin mainly targets the endoplasmic reticulum (ER) and lysosomes. The classic apoptotic pathway is mediated by calcium release from the ER. Uptake of this calcium by mitochondria disrupts mitochondrial homeostasis. Calcium alters mitochondrial electron transport causing substantial ROS production (both superoxide anions and hydrogen peroxide), which leads to the opening of the permeability transition pore in the mitochondrial membrane. Consequently, cytochrome $c$ is released and the caspase- 9 and caspase-3/7 pathway is activated leading to cell death. Furthermore, the ER stress pathway leads to the formation of autophagic vacuoles that attempt to eliminate the dysfunctional mitochondria. The cleavage of beclin-1 is associated with early apoptosis and leads to the accumulation of autophagic vacuoles. So, despite the activation of autophagy, cells undergo a type of "necrotic cell death" following these initial apoptotic events. These two pathways are in parallel to a lysosomal pathway that is dependent on curcumin concentration (see Figure 4). Curcumin destabilizes lysosomal membranes leading to lysosomal membrane permeability and the activation of both cathepsins and chemotrypsins. Activated caspase- 8 leads to beclin-1 cleavage that inhibits the primarily induced autophagy. The increase in cytosolic calcium concentration also activates calpains, which contribute to the degradation process and accelerate cell death. The various inhibitors used in this work are indicated in red at the place where the pathways are affected $([2,39]$; and Patrice X. Petit personnal communication). Big gray arrows indicate the entrance of the three main pathways that interfere (primary cell death pathway, secondary lysosomal cell death pathway, and autophagic pathway).

Beyond curcumin, knowledge of the role of natural chemopreventive agents in autophagy and apoptosis will certainly expand [208] and may lead to anticancer therapies with minimal adverse effects [209]. The study of the role of natural agents that induce beneficial cross-talk between apoptosis and autophagy to finely tune cell death is also at the forefront of new therapeutic discoveries in metabolic disorders and aging.

\section{Abbreviations}

\section{AP1:}

Caspase-10:

EphA2:
Activator protein 1 (AP-1), a transcription factor

Cleaves and activates caspase- 3 and caspase-7, and the protein itself is processed by caspase- 8

EPH receptor A2 (ephrin type-A receptor 2) is a protein encoded by the EPHA2 gene and belongs to the ephrin receptor subfamily of the proteintyrosine kinase family

EZH2: $\quad$ Enhancer of zeste homolog 2 is a histonelysine N-methyltransferase enzyme (EC 2.1.1.43) encoded by the EZH2 gene which participates in DNA methylation and transcriptional repression

ESR1: $\quad$ Estrogen receptor 1

FOXO1: Forkhead box protein O1, also known as forkhead in rhabdomyosarcoma, is a protein that in humans is encoded by the FOXO1 gene

GRP78: Member of the HSP family of molecular chaperones required for endoplasmic reticulum integrity and stress-induced autophagy

Nfr2: Nuclear factor (erythroid-derived 2)like 2, also known as NFE2L2, is a basic leucine zipper (bZIP) protein that 
regulates the expression of antioxidant proteins that protect against oxidative damage triggered by injury and inflammation

Pcdc4: $\quad$ Programmed cell death protein 4 target of the oncomiR miR-21

PTEN: Gene that was identified as a tumor suppressor that is mutated in a large number of cancers at high frequency Skp2: S-phase kinase-associated protein 2 SOCS1 and SOCS3: Genes that encode members of the STAT-induced STAT inhibitor family (SSI), also known as suppressors of cytokine signaling (SOCS)

SP1: Protein encoded by this gene is a zinc finger transcription factor that binds to GC-rich motifs of many promoters.

\section{Conflicts of Interest}

The authors declare no conflicts of interest.

\section{Authors' Contributions}

Patrice X. Petit, Nathan E. Rainey, and Aoula Moustapha have equally contributed to the redaction of this article. Nathan E. Rainey and Aoula Moustapha both produce a $\mathrm{PhD}$ thesis related to this topic in December 2019 and 2015, respectively, and authored some important articles in the field of curcumin chemistry and functional physiology that have been published in international journals.

\section{Acknowledgments}

This work was funded with basic support from both the "Centre National de la Recherche Scientifique" (CNRS) and the "Institut National de La Santé et de la Recherche Medicale" (INSERM) to Patrice X. Petit. Nathan E. Rainey is supported by a $\mathrm{PhD}$ grant from "Université Sorbonne Paris Cité." AFM (Association Française contre les Myopathies, grants 15137 and 15661) funding was also used for this work. We also thank Raphael Parker (Paris University) for his intervention on an early assessment of the manuscript.

\section{References}

[1] K. Priyadarsini, "The chemistry of curcumin: from extraction to therapeutic agent," Molecules, vol. 19, no. 12, pp. 2009120112, 2014.

[2] A. Moustapha, P. A. Pérétout, N. E. Rainey et al., "Curcumin induces crosstalk between autophagy and apoptosis mediated by calcium release from the endoplasmic reticulum, lysosomal destabilization and mitochondrial events," Cell Death Discovery, vol. 1, no. 1, 2015.

[3] F. J. Sala de Oyanguren, N. E. Rainey, A. Moustapha et al., "Highlighting curcumin-induced crosstalk between autophagy and apoptosis as supported by its specific subcellular localization," Cell, vol. 9, no. 2, p. 361, 2020.
[4] V. Lampe and J. Milobedzka, "Studien über curcumin," Berichte der Deutschen Chemischen Gesellschaft, vol. 46, no. 2, pp. 2235-2240, 1913.

[5] H. J. J. Pabon, "A Synthesis of curcumin and related compounds," Recueil des Travaux Chimiques des Pays-Bas, vol. 83, no. 4, pp. 379-386, 1964.

[6] K. V. D. Babu and K. N. Rajasekharan, "Simplified condition for synthesis of curcumin I and other curcuminoids," Organic Preparations and Procedures International, vol. 26, no. 6, pp. 674-677, 1994.

[7] E. V. Rao, Y. R. Prasad, and P. Sudheer, "Revisiting curcumin Chemistry- part II: synthesis of Monomethylcurcumin and Isomeric Demethoxycurcumins and their Characterization," Indian Journal of Pharmaceutical Sciences, vol. 79, no. 5, 2017.

[8] S. Venkateswarlu, M. S. Ramachandra, and G. V. Subbaraju, "Synthesis and biological evaluation of polyhydroxycurcuminoids," Bioorganic \& Medicinal Chemistry, vol. 13, no. 23, pp. 6374-6380, 2005.

[9] I. Ali, A. Haque, and K. Saleem, "Separation and identification of curcuminoids in turmeric powder by HPLC using phenyl column," Analytical Methods, vol. 6, no. 8, pp. 2526-2536, 2014.

[10] K. J. Lee, Y. S. Kim, and J. Y. Ma, "Separation and identification of curcuminoids from Asian turmeric (Curcuma longa L.) using RP-HPLC and LC-MS," Asian Journal of Chemistry, vol. 25, no. 2, pp. 909-912, 2013.

[11] O. P. Sharma, "Antioxidant activity of curcumin and related compounds," Biochemical Pharmacology, vol. 25, no. 15, pp. 1811-1812, 1976.

[12] K. I. Priyadarsini, "Photophysics, photochemistry and photobiology of curcumin: studies from organic solutions, biomimetics and living cells," Journal of Photochemistry and Photobiology C, vol. 10, no. 2, pp. 81-95, 2009.

[13] K. Mohammadi, K. H. Thompson, B. O. Patrick et al., "Synthesis and characterization of dual function vanadyl, gallium and indium curcumin complexes for medicinal applications," Journal of Inorganic Biochemistry, vol. 99, no. 11, pp. 22172225, 2005.

[14] A. Barik, B. Mishra, L. Shen et al., "Evaluation of a new copper(II)-curcumin complex as superoxide dismutase mimic and its free radical reactions," Free Radical Biology \& Medicine, vol. 39, no. 6, pp. 811-822, 2005.

[15] P. R. Koiram, V. P. Veerapur, A. Kunwar et al., "Effect of curcumin and curcumin copper complex $(1: 1)$ on radiationinduced changes of anti-oxidant enzymes levels in the livers of Swiss albino mice," Journal of Radiation Research, vol. 48, no. 3, pp. 241-245, 2007.

[16] O. Vajragupta, P. Boonchoong, and L. J. Berliner, "Manganese complexes of curcumin analogues: evaluation of hydroxyl radical scavenging ability, superoxide dismutase activity and stability towards hydrolysis," Free Radical Research, vol. 38, no. 3, pp. 303-314, 2009.

[17] A. Kunwar, H. Narang, K. I. Priyadarsini, M. Krishna, R. Pandey, and K. B. Sainis, "Delayed activation of PKC $\delta$ and $\mathrm{NF} \kappa \mathrm{B}$ and higher radioprotection in splenic lymphocytes by copper (II)-curcumin (1:1) complex as compared to curcumin," Journal of Cellular Biochemistry, vol. 102, no. 5, pp. 1214-1224, 2007.

[18] L. Baum and A. Ng, "Curcumin interaction with copper and iron suggests one possible mechanism of action in 
Alzheimer's disease animal models," Journal of Alzheimer's Disease, vol. 6, no. 4, pp. 367-377, 2004.

[19] T. Jiang, X. L. Zhi, Y. H. Zhang, L. F. Pan, and P. Zhou, "Inhibitory effect of curcumin on the $\mathrm{Al}(\mathrm{III})$-induced $\mathrm{A} \beta_{42}$ aggregation and neurotoxicity in vitro," Biochimica et Biophysica Acta, vol. 1822, no. 8, pp. 1207-1215, 2012.

[20] N. E. Rainey, A. Moustapha, A. Saric, G. Nicolas, F. Sureau, and P. X. Petit, "Iron chelation by curcumin suppresses both curcumin-induced autophagy and cell death together with iron overload neoplastic transformation," Cell Death Discovery, vol. 5, no. 1, 2019.

[21] G. J. Szebeni, Á. Balázs, I. Madarász et al., “Achiral Mannichbase curcumin analogs induce unfolded protein response and mitochondrial membrane depolarization in PANC-1 cells," International Journal of Molecular Sciences, vol. 18, no. 10, p. 2105, 2017.

[22] M. Asti, E. Ferrari, S. Croci et al., "Synthesis and characterization of (68) Ga-labeled curcumin and curcuminoid complexes as potential radiotracers for imaging of cancer and Alzheimer's disease," Inorganic Chemistry, vol. 53, no. 10, pp. 4922-4933, 2014.

[23] E. Ferrari, M. Asti, R. Benassi, F. Pignedoli, and M. Saladini, "Metal binding ability of curcumin derivatives: a theoretical vs. experimental approach," Dalton Transactions, vol. 42, no. 15, pp. 5304-5313, 2013.

[24] M. I. Khalil, A. M. Al-Zahem, and M. H. Al-Qunaibit, "Synthesis, Characterization, Mössbauer Parameters, and Antitumor Activity of Fe(III) Curcumin Complex," Bioinorganic Chemistry and Applications, vol. 2013, 5 pages, 2013.

[25] H. Oguzturk, O. Ciftci, M. Aydin, N. Timurkaan, A. Beytur, and F. Yilmaz, "Ameliorative effects of curcumin against acute cadmium toxicity on male reproductive system in rats," Andrologia, vol. 44, no. 4, pp. 243-249, 2012.

[26] R. Pallikkavil, M. B. Ummathur, S. Sreedharan, and K. Krishnankutty, "Synthesis, characterization and antimicrobial studies of $\mathrm{Cd}(\mathrm{II}), \mathrm{Hg}(\mathrm{II}), \mathrm{Pb}(\mathrm{II}), \mathrm{Sn}(\mathrm{II})$ and $\mathrm{Ca}(\mathrm{II})$ complexes of curcumin," Main Group Metal Chemistry, vol. 36, no. 3-4, pp. 123-127, 2013.

[27] A. Valentini, F. Conforti, A. Crispini et al., "Synthesis, oxidant properties, and antitumoral effects of a heteroleptic palladium(II) complex of curcumin on human prostate cancer cells," Journal of Medicinal Chemistry, vol. 52, no. 2, pp. 484-491, 2009.

[28] T. Ak and I. Gulcin, "Antioxidant and radical scavenging properties of curcumin," Chemico-Biological Interactions, vol. 174, no. 1, pp. 27-37, 2008.

[29] M. Borsari, E. Ferrari, R. Grandi, and M. Saladini, "Curcuminoids as potential new iron-chelating agents: spectroscopic, polarographic and potentiometric study on their Fe(III) complexing ability," Inorganic Chemistry Acta, vol. 328, no. 1, pp. 61-68, 2002.

[30] Y. Jiao, J. Wilkinson IV, E. Christine Pietsch et al., "Iron chelation in the biological activity of curcumin," Free Radical Biology and Medicine, vol. 40, no. 7, pp. 1152-1160, 2006.

[31] A. Barik, B. Mishra, A. Kunwar et al., "Comparative study of copper(II)-curcumin complexes as superoxide dismutase mimics and free radical scavengers," European Journal of Medicinal Chemistry, vol. 42, no. 4, pp. 431-439, 2007.

[32] K. I. Priyadarsini, "Chemical and structural features influencing the biological activity of curcumin," Current Pharmaceutical Design, vol. 19, no. 11, pp. 2093-2100, 2013.
[33] S. Wanninger, V. Lorenz, A. Subhan, and F. T. Edelmann, "Metal complexes of curcumin-synthetic strategies, structures and medicinal applications," Chemical Society Reviews, vol. 44, no. 15, pp. 4986-5002, 2015.

[34] A. Goel and B. B. Aggarwal, "Curcumin, the golden spice from Indian saffron, is a chemosensitizer and radiosensitizer for tumors and chemoprotector and radioprotector for normal organs," Nutrition and Cancer, vol. 62, no. 7, pp. 919930, 2010.

[35] S. C. Gupta, B. Sung, J. H. Kim, S. Prasad, S. Li, and B. B. Aggarwal, "Multitargeting by turmeric, the golden spice: from kitchen to clinic," Molecular Nutrition \& Food Research, vol. 57, no. 9, pp. 1510-1528, 2013.

[36] D. J. Messner, T. Robinson, and K. V. Kowdley, "Curcumin and turmeric modulate the tumor-promoting effects of iron in vitro," Nutrition and Cancer, vol. 69, no. 3, pp. 481-489, 2017.

[37] S. Prasad, S. C. Gupta, A. K. Tyagi, and B. B. Aggarwal, "Curcumin, a component of golden spice: from bedside to bench and back," Biotechnology Advances, vol. 32, no. 6, pp. 10531064, 2014.

[38] S. Prasad, A. K. Tyagi, and B. B. Aggarwal, "Recent developments in delivery, bioavailability, absorption and metabolism of curcumin: the golden pigment from golden spice," Cancer Research and Treatment, vol. 46, no. 1, pp. 2-18, 2014.

[39] N. Rainey, L. Motte, B. B. Aggarwal, and P. X. Petit, "Curcumin hormesis mediates a cross-talk between autophagy and cell death," Cell Death \& Disease, vol. 6, no. 12, p. e2003, 2015.

[40] M. H. Leung, T. Harada, and T. W. Kee, "Delivery of curcumin and medicinal effects of the copper(II)-curcumin complexes," Current Pharmaceutical Design, vol. 19, no. 11, pp. 2070-2083, 2013.

[41] O. Vajragupta, P. Boonchoong, H. Watanabe, M. Tohda, N. Kummasud, and Y. Sumanont, "Manganese complexes of curcumin and its derivatives: evaluation for the radical scavenging ability and neuroprotective activity," Free Radical Biology \& Medicine, vol. 35, no. 12, pp. 1632-1644, 2003.

[42] T. Jiang, L. Wang, S. Zhang et al., "Interaction of curcumin with $\mathrm{Al}(\mathrm{III})$ and its complex structures based on experiments and theoretical calculations," Journal of Molecular Structure, vol. 1004, no. 1-3, pp. 163-173, 2011.

[43] M. Gianluca, F. Erika, L. Gigliola et al., "The role of coordination chemistry in the development of innovative gallium-based bioceramics: the case of curcumin," Journal of Materials Chemistry, vol. 21, no. 13, p. 5027, 2011.

[44] X. Mei, D. Xu, S. Xu, Y. Zheng, and S. Xu, "Gastroprotective and antidepressant effects of a new zinc(II)-curcumin complex in rodent models of gastric ulcer and depression induced by stresses," Pharmacology, Biochemistry, and Behavior, vol. 99, no. 1, pp. 66-74, 2011.

[45] D. Pucci, T. Bellini, A. Crispini et al., "DNA binding and cytotoxicity of fluorescent curcumin-based $\mathrm{Zn}$ (II) complexes," Medicinal Chemistry Communications, vol. 3, no. 4, p. 462, 2012.

[46] K. K. Sharma, S. Chandra, and D. K. Basu, "Synthesis and antiarthritic study of a new orally active diferuloyl methane (curcumin) gold complex," Inorganica Chimica Acta, vol. 135, no. 1, pp. 47-48, 1987.

[47] K. H. Thompson, K. Bohmerle, E. Polishchuk et al., "Complementary inhibition of synoviocyte, smooth muscle cell or mouse lymphoma cell proliferation by a vanadyl curcumin 
complex compared to curcumin alone," Journal of Inorganic Biochemistry, vol. 98, no. 12, pp. 2063-2070, 2004.

[48] R. Agarwal, S. K. Goel, and J. R. Behari, "Detoxification and antioxidant effects of curcumin in rats experimentally exposed to mercury," Journal of Applied Toxicology, vol. 30, no. 5, pp. 457-468, 2010.

[49] S. Daniel, J. L. Limson, A. Dairam, G. M. Watkins, and S. Daya, "Through metal binding, curcumin protects against lead- and cadmium-induced lipid peroxidation in rat brain homogenates and against lead-induced tissue damage in rat brain," Journal of Inorganic Biochemistry, vol. 98, no. 2, pp. 266-275, 2004.

[50] V. Eybl, D. Kotyzová, L. Lešetický, M. Bludovská, and J. Koutenský, "The influence of curcumin and manganese complex of curcumin on cadmium-induced oxidative damage and trace elements status in tissues of mice," Journal of Applied Toxicology, vol. 26, no. 3, pp. 207-212, 2006.

[51] J. Rennolds, S. Malireddy, F. Hassan et al., "Curcumin regulates airway epithelial cell cytokine responses to the pollutant cadmium," Biochemical and Biophysical Research Communications, vol. 417, no. 1, pp. 256-261, 2012.

[52] M. O. Iwunze and D. McEwan, "Peroxynitrite interaction with curcumin solubilized in ethanolic solution," Cellular and Molecular Biology (Noisy-le-Grand, France), vol. 50, pp. 749-752, 2004.

[53] S. V. Jovanovic, C. W. Boone, S. Steenken, M. Trinoga, and R. B. Kaskey, "How curcumin works preferentially with water soluble antioxidants," Journal of the American Chemical Society, vol. 123, no. 13, pp. 3064-3068, 2001.

[54] J. E. Kim, A. R. Kim, H. Y. Chung, S. Y. Han, B. S. Kim, and J. S. Choi, "In vitro peroxynitrite scavenging activity of diarylheptanoids from Curcuma longa," Phytotherapy Research, vol. 17, no. 5, pp. 481-484, 2003.

[55] B. Mishra, K. I. Priyadarsini, M. K. Bhide, R. M. Kadam, and H. Mohan, "Reactions of superoxide radicals with curcumin: probable mechanisms by optical spectroscopy and EPR," Free Radical Research, vol. 38, no. 4, pp. 355-362, 2009.

[56] K. I. Priyadarsini, "Free radical reactions of curcumin in membrane models," Free Radical Biology \& Medicine, vol. 23, no. 6, pp. 838-843, 1997.

[57] K. I. Priyadarsini, D. K. Maity, G. H. Naik et al., "Role of phenolic $\mathrm{O}-\mathrm{H}$ and methylene hydrogen on the free radical reactions and antioxidant activity of curcumin," Free Radical Biology \& Medicine, vol. 35, no. 5, pp. 475-484, 2003.

[58] Y. M. Sun, H. Y. Zhang, D. Z. Chen, and C. B. Liu, "Theoretical elucidation on the antioxidant mechanism of curcumin: a DFT study," Organic Letters, vol. 4, no. 17, pp. 2909-2911, 2002.

[59] M. Roy and S. Mukherjee, "Reversal of resistance towards cisplatin by curcumin in cervical cancer cells," Asian Pacific Journal of Cancer Prevention, vol. 15, no. 3, pp. 1403-1410, 2014.

[60] M. T. Kuo, "Redox regulation of multidrug resistance in cancer chemotherapy: molecular mechanisms and therapeutic opportunities," Antioxidants \& Redox Signaling, vol. 11, no. 1, pp. 99-133, 2009.

[61] W. Song, R. Jiang, and C. M. Zhao, "Role of integrin-linked kinase in multi-drug resistance of human gastric carcinoma SGC7901/DDP cells," Asian Pacific Journal of Cancer Prevention, vol. 13, no. 11, pp. 5619-5625, 2012.
[62] C. N. Sreekanth, S. V. Bava, E. Sreekumar, and R. J. Anto, "Molecular evidences for the chemosensitizing efficacy of liposomal curcumin in paclitaxel chemotherapy in mouse models of cervical cancer," Oncogene, vol. 30, no. 28, pp. 3139-3152, 2011.

[63] P. Javvadi, A. T. Segan, S. W. Tuttle, and C. Koumenis, "The chemopreventive agent curcumin is a potent radiosensitizer of human cervical tumor cells via increased reactive oxygen species production and overactivation of the mitogenactivated protein kinase pathway," Molecular Pharmacology, vol. 73, no. 5, pp. 1491-1501, 2008.

[64] B. B. Aggarwal, S. Shishodia, Y. Takada et al., "Curcumin suppresses the paclitaxel-induced nuclear factor- $\kappa \mathrm{B}$ pathway in breast cancer cells and inhibits lung metastasis of human breast cancer in nude mice," Clinical Cancer Research, vol. 11, no. 20, pp. 7490-7498, 2005.

[65] Y. P. Dang, X. Y. Yuan, R. Tian, D. G. Li, and W. Liu, "Curcumin improves the paclitaxel-induced apoptosis of HPV-positive human cervical cancer cells via the NF- $\kappa \mathrm{B}-$ p53-caspase-3 pathway," Experimental and Therapeutic Medicine, vol. 9, no. 4, pp. 1470-1476, 2015.

[66] P. Anand, S. G. Thomas, A. B. Kunnumakkara et al., "Biological activities of curcumin and its analogues (Congeners) made by man and Mother Nature," Biochemical Pharmacology, vol. 76, no. 11, pp. 1590-1611, 2008.

[67] K. S. Bhullar, A. Jha, and H. P. V. Rupasinghe, "Novel carbocyclic curcumin analog CUR3d modulates genes involved in multiple apoptosis pathways in human hepatocellular carcinoma cells," Chemico-Biological Interactions, vol. 242, pp. 107-122, 2015.

[68] H. Gali-Muhtasib, R. Hmadi, M. Kareh, R. Tohme, and N. Darwiche, "Cell death mechanisms of plant-derived anticancer drugs: beyond apoptosis," Apoptosis, vol. 20, no. 12, pp. 1531-1562, 2015.

[69] M. Hosseinzadehdehkordi, A. Adelinik, and A. Tashakor, "Dual effect of curcumin targets reactive oxygen species, adenosine triphosphate contents and intermediate steps of mitochondria-mediated apoptosis in lung cancer cell lines," European Journal of Pharmacology, vol. 769, pp. 203-210, 2015.

[70] J. Sun, Y. Zhao, H. Jin, and J. Hu, "Curcumin relieves TPAinduced Th1 inflammation in K14-VEGF transgenic mice," International Immunopharmacology, vol. 25, no. 2, pp. 235241, 2015.

[71] G. Weng, Y. Zeng, J. Huang, J. Fan, and K. Guo, "Curcumin enhanced busulfan-induced apoptosis through downregulating the expression of survivin in leukemia stem-like KGla cells," BioMed Research International, vol. 2015, Article ID 630397, 16 pages, 2015.

[72] O. J. F. Banji, D. Banji, and K. Ch, "Curcumin and hesperidin improve cognition by suppressing mitochondrial dysfunction and apoptosis induced by D-galactose in rat brain," Food and Chemical Toxicology, vol. 74, pp. 51-59, 2014.

[73] A. Priyanka, S. S. Anusree, V. M. Nisha, and K. G. Raghu, "Curcumin improves hypoxia induced dysfunctions in 3T3L1 adipocytes by protecting mitochondria and down regulating inflammation," Biofactors, vol. 40, no. 5, pp. 513-523, 2014.

[74] K. Rashid and P. C. Sil, "Curcumin ameliorates testicular damage in diabetic rats by suppressing cellular stress-mediated mitochondria and endoplasmic reticulum-dependent 
apoptotic death," Biochimica et Biophysica Acta, vol. 1852, no. 1, pp. 70-82, 2015.

[75] K. Rashid and P. C. Sil, "Curcumin enhances recovery of pancreatic islets from cellular stress induced inflammation and apoptosis in diabetic rats," Toxicology and Applied Pharmacology, vol. 282, no. 3, pp. 297-310, 2015.

[76] W. Cai, B. Zhang, D. Duan, J. Wu, and J. Fang, "Curcumin targeting the thioredoxin system elevates oxidative stress in HeLa cells," Toxicology and Applied Pharmacology, vol. 262, no. 3, pp. 341-348, 2012.

[77] A. K. Singh and K. Misra, "Human papilloma virus 16 E6 protein as a target for curcuminoids, curcumin conjugates and congeners for chemoprevention of oral and cervical cancers," Interdisciplinary Sciences, vol. 5, no. 2, pp. 112-118, 2013.

[78] D. J. Klionsky, “Autophagy participates in, well, just about everything," Cell Death and Differentiation, vol. 27, no. 3, pp. 831-832, 2020.

[79] Z. Yang and D. J. Klionsky, "Mammalian autophagy: core molecular machinery and signaling regulation," Current Opinion in Cell Biology, vol. 22, no. 2, pp. 124-131, 2010.

[80] J. Geng and D. J. Klionsky, "Determining Atg protein stoichiometry at the phagophore assembly site by fluorescence microscopy," Autophagy, vol. 6, no. 1, pp. 144-147, 2010.

[81] M. Cicchini, R. Chakrabarti, S. Kongara et al., "Autophagy regulator BECN1 suppresses mammary tumorigenesis driven by WNT1 activation and following parity," Autophagy, vol. 10, no. 11, pp. 2036-2052, 2014.

[82] X. Qu, J. Yu, G. Bhagat et al., "Promotion of tumorigenesis by heterozygous disruption of the beclin 1 autophagy gene," The Journal of Clinical Investigation, vol. 112, no. 12, pp. 18091820, 2003.

[83] Z. Yue, S. Jin, C. Yang, A. J. Levine, and N. Heintz, "Beclin 1 , an autophagy gene essential for early embryonic development, is a haploinsufficient tumor suppressor," Proceedings of the National Academy of Sciences of the United States of America, vol. 100, no. 25, pp. 15077-15082, 2011.

[84] R.-A. Gonzalez-Polo, "The apoptosis/autophagy paradox: autophagic vacuolization before apoptotic death," Journal of Cell Science, vol. 118, no. 14, pp. 3091-3102, 2005.

[85] J. J. Lum, R. J. DeBerardinis, and C. B. Thompson, “Autophagy in metazoans: cell survival in the land of plenty," Nature Reviews. Molecular Cell Biology, vol. 6, no. 6, pp. 439-448, 2005.

[86] N. Chen and V. Karantza, "Autophagy as a therapeutic target in cancer," Cancer Biology \& Therapy, vol. 11, no. 2, pp. 157168, 2014.

[87] S. Pandey and C. Chandravati, "Autophagy in cervical cancer: an emerging therapeutic target," Asian Pacific Journal of Cancer Prevention, vol. 13, no. 10, pp. 4867-4871, 2012.

[88] R. S. DiPaola, D. Dvorzhinski, A. Thalasila et al., "Therapeutic starvation and autophagy in prostate cancer: a new paradigm for targeting metabolism in cancer therapy," Prostate, vol. 68 , no. 16 , pp. 1743-1752, 2008.

[89] V. Karantza and E. White, "Role of autophagy in breast cancer," Autophagy, vol. 3, no. 6, pp. 610-613, 2014.

[90] Q. Kang and A. Chen, "Curcumin inhibits srebp-2 expression in activated hepatic stellate cells in vitro by reducing the activity of specificity protein-1," Endocrinology, vol. 150, no. 12, pp. 5384-5394, 2009.
[91] W. Gao, J. Y.-W. Chan, W. I. Wei, and T.-S. Wong, "Anticancer effects of curcumin on head and neck cancers," AntiCancer Agents in Medicinal Chemistry, vol. 12, no. 9, pp. 1110-1116, 2012.

[92] T. Plengsuriyakarn, V. Viyanant, V. Eursitthichai et al., "Cytotoxicity, toxicity, and anticancer activity of Zingiber officinale Roscoe against cholangiocarcinoma," Asian Pacific Journal of Cancer Prevention, vol. 13, no. 9, pp. 4597-4606, 2012.

[93] D. Y. Zhou, N. Ding, Z. Y. Du et al., "Curcumin analogues with high activity for inhibiting human prostate cancer cell growth and androgen receptor activation," Molecular Medicine Reports, vol. 10, no. 3, pp. 1315-1322, 2014.

[94] J. Odot, P. Albert, A. Carlier, M. Tarpin, J. Devy, and C. Madoulet, "In vitro and in vivo anti-tumoral effect of curcumin against melanoma cells," International Journal of Cancer, vol. 111, no. 3, pp. 381-387, 2004.

[95] S. S. Bansal, M. Goel, F. Aqil, M. V. Vadhanam, and R. C. Gupta, "Advanced drug delivery systems of curcumin for cancer chemoprevention," Cancer Prevention Research, vol. 4, no. 8, pp. 1158-1171, 2011.

[96] H. J. Kang, S. H. Lee, J. E. Price, and L. S. Kim, "Curcumin suppresses the paclitaxel-induced nuclear factor-kappaB in breast cancer cells and potentiates the growth inhibitory effect of paclitaxel in a breast cancer nude mice model," The Breast Journal, vol. 15, no. 3, pp. 223-229, 2009.

[97] S.-J. Lee, H.-P. Kim, Y. Jin, A. M. K. Choi, and S. W. Ryter, "Beclin 1 deficiency is associated with increased hypoxiainduced angiogenesis," Autophagy, vol. 7, no. 8, pp. 829839, 2014.

[98] H. Aoki, Y. Takada, S. Kondo, R. Sawaya, B. B. Aggarwal, and Y. Kondo, "Evidence that curcumin suppresses the growth of malignant gliomas in vitro and in vivo through induction of autophagy: role of Akt and extracellular signal-regulated kinase signaling pathways," Molecular Pharmacology, vol. 72, no. 1, pp. 29-39, 2007.

[99] Y.-L. Jia, J. Li, Z.-H. Qin, and Z.-Q. Liang, “Autophagic and apoptotic mechanisms of curcumin-induced death in K562 cells," Journal of Asian Natural Products Research, vol. 11, no. 11, pp. 918-928, 2009.

[100] H. Qian, Y. Yang, and X. Wang, "Curcumin enhanced adriamycin-induced human liver-derived hepatoma G2 cell death through activation of mitochondria-mediated apoptosis and autophagy," European Journal of Pharmaceutical Sciences, vol. 43, no. 3, pp. 125-131, 2011.

[101] O. Ozmen and F. Mor, "Effects of vitamin C on pathology and caspase-3 activity of kidneys with subacute endosulfan toxicity," Biotechnic \& Histochemistry, vol. 90, no. 1, pp. 25-30, 2014.

[102] D. Rastogi, R. Narayan, D. K. Saxena, and D. K. Chowdhuri, "Endosulfan induced cell death in Sertoli-germ cells of male Wistar rat follows intrinsic mode of cell death," Chemosphere, vol. 94, pp. 104-115, 2014.

[103] B. Shao, L. Zhu, M. Dong et al., "DNA damage and oxidative stress induced by endosulfan exposure in zebrafish (Danio rerio)," Ecotoxicology, vol. 21, no. 5, pp. 1533-1540, 2012.

[104] H. Y. Sohn, C. S. Kwon, G. S. Kwon, J. B. Lee, and E. Kim, "Induction of oxidative stress by endosulfan and protective effect of lipid- soluble antioxidants against endosulfaninduced oxidative damage," Toxicology Letters, vol. 151, no. 2, pp. 357-365, 2004. 
[105] I. A. Zervos, E. Nikolaidis, S. N. Lavrentiadou et al., "Endosulfan-induced lipid peroxidation in rat brain and its effect on t-PA and PAI-1: ameliorating effect of vitamins C and E," The Journal of Toxicological Sciences, vol. 36, no. 4, pp. 423-433, 2011.

[106] E. H. Han, H. G. Kim, E. J. Lee, and H. G. Jeong, "Endosulfan induces CYP1A1 expression mediated through aryl hydrocarbon receptor signal transduction by protein kinase C," Toxicology Research, vol. 31, no. 4, pp. 339345, 2015.

[107] N. S. Srikanth, P. K. Seth, and D. Desaiah, "Inhibition of calmodulin-activated Ca2(-)-ATPase by endosulfan in rat brain," Journal of Toxicology and Environmental Health, vol. 28, no. 4, pp. 473-481, 1989.

[108] T. Ahmed, A. K. Tripathi, R. S. Ahmed et al., "Endosulfaninduced apoptosis and glutathione depletion in human peripheral blood mononuclear cells: attenuation by $\mathrm{N}$-acetylcysteine," Journal of Biochemical and Molecular Toxicology, vol. 22, no. 5, pp. 299-304, 2008.

[109] K. Kannan, R. F. Holcombe, S. K. Jain et al., "Evidence for the induction of apoptosis by endosulfan in a human T-cell leukemic line," Molecular and Cellular Biochemistry, vol. 205, no. 1/2, pp. 53-66, 2000.

[110] O. Ozmen, "Cardiotoxicity and apoptotic activity in subacute endosulfan toxicity and the protective effect of vitamin $C$ in rabbits: a pathological study," Journal of Environmental Pathology, Toxicology and Oncology, vol. 32, no. 1, pp. 5358, 2013.

[111] Y. Xu, N. Wang, Z. X. Shi, Y. B. Li, X. Q. Zhou, and Z. W. Sun, "The mechanism study of endosulfan-induced spermatogenic cell apoptosis of mouse in vitro," Toxicology and Industrial Health, pp. 1-14, 2015.

[112] S. Aggarwal, Y. Takada, S. Singh, J. N. Myers, and B. B. Aggarwal, "Inhibition of growth and survival of human head and neck squamous cell carcinoma cells by curcumin via modulation of nuclear factor-?B signaling," International Journal of Cancer, vol. 111, no. 5, pp. 679-692, 2004.

[113] A. C. Bharti, Y. Takada, S. Shishodia, and B. B. Aggarwal, "Evidence that receptor activator of nuclear factor (NF) $-\kappa B$ ligand can suppress cell proliferation and induce apoptosis through activation of a NF- $\kappa \mathrm{B}$-independent and TRAF6dependent mechanism," The Journal of Biological Chemistry, vol. 279, no. 7, pp. 6065-6076, 2004.

[114] S. Singh and B. B. Aggarwal, "Activation of transcription factor NF-kappa B is suppressed by curcumin (diferuloylmethane) [corrected]," The Journal of Biological Chemistry, vol. 270, no. 42, pp. 24995-25000, 1995.

[115] S. Aggarwal, H. Ichikawa, Y. Takada, S. K. Sandur, S. Shishodia, and B. B. Aggarwal, "Curcumin (diferuloylmethane) down-regulates expression of cell proliferation and antiapoptotic and metastatic gene products through suppression of $\mathrm{I} \kappa \mathrm{B} \alpha$ kinase and Akt activation," Molecular Pharmacology, vol. 69, no. 1, pp. 195-206, 2006.

[116] A. C. Bharti, N. Donato, and B. B. Aggarwal, "Curcumin (diferuloylmethane) inhibits constitutive and IL-6-inducible STAT3 phosphorylation in human multiple myeloma cells," Journal of Immunology, vol. 171, no. 7, pp. 38633871, 2003.

[117] A. Mukhopadhyay, S. Banerjee, L. J. Stafford, C. Xia, M. Liu, and B. B. Aggarwal, "Curcumin-induced suppression of cell proliferation correlates with down- regulation of cyclin D1 expression and CDK4-mediated retinoblastoma protein phosphorylation,” Oncogene, vol. 21, no. 57, pp. 8852-8861, 2002.

[118] S. V. Bava, V. T. Puliappadamba, A. Deepti, A. Nair, D. Karunagaran, and R. J. Anto, "Sensitization of taxolinduced apoptosis by curcumin involves down-regulation of nuclear factor- $\kappa \mathrm{B}$ and the serine/threonine kinase Akt and is independent of tubulin polymerization," The Journal of Biological Chemistry, vol. 280, no. 8, pp. 6301-6308, 2005.

[119] C. S. Beevers, L. Chen, L. Liu, Y. Luo, N. J. G. Webster, and S. Huang, "Curcumin disrupts the mammalian target of rapamycin-raptor complex," Cancer Research, vol. 69, no. 3, pp. 1000-1008, 2009.

[120] J. H. Woo, Y. H. Kim, Y. J. Choi et al., "Molecular mechanisms of curcumin-induced cytotoxicity: induction of apoptosis through generation of reactive oxygen species, down-regulation of Bcl-XL and IAP, the release of cytochrome c and inhibition of Akt," Carcinogenesis, vol. 24, no. 7, pp. 1199-1208, 2003.

[121] A. Chen, J. Xu, and A. C. Johnson, "Curcumin inhibits human colon cancer cell growth by suppressing gene expression of epidermal growth factor receptor through reducing the activity of the transcription factor Egr-1," Oncogene, vol. 25, no. 2, pp. 278-287, 2006.

[122] K. Nakamura, Y. Yasunaga, T. Segawa et al., "Curcumin down-regulates AR gene expression and activation in prostate cancer cell lines," International Journal of Oncology, vol. 21, no. 4, pp. 825-830, 2002.

[123] B. K. Prusty and B. C. Das, "Constitutive activation of transcription factor AP-1 in cervical cancer and suppression of human papillomavirus (HPV) transcription and AP-1 activity in HeLa cells by curcumin," International Journal of Cancer, vol. 113, no. 6, pp. 951-960, 2005.

[124] M. Tomita, H. Kawakami, J. N. Uchihara et al., "RETRACTED: Curcumin suppresses constitutive activation of AP-1 by downregulation of JunD protein in HTLV-1infected T-cell lines," Leukemia Research, vol. 30, no. 3, pp. 313-321, 2006.

[125] M. Tomita, T. Matsuda, H. Kawakami et al., "Curcumin targets Akt cell survival signaling pathway in HTLV-I-infected T-cell lines," Cancer Science, vol. 97, no. 4, pp. 322-327, 2006.

[126] S. Z. Moghadamtousi, H. A. Kadir, P. Hassandarvish, H. Tajik, S. Abubakar, and K. Zandi, "A review on antibacterial, antiviral, and antifungal activity of curcumin," BioMed Research International, vol. 2014, 12 pages, 2014.

[127] S.-S. Han, Y.-S. Keum, H.-J. Seo, and Y.-J. Surh, "Curcumin suppresses activation of NF- $\kappa$ B and AP-1 induced by phorbol ester in cultured human promyelocytic leukemia cells," Journal of Biochemistry and Molecular Biology, vol. 35, no. 3, pp. 337-342, 2002.

[128] J. Tabeshpour, S. Banaeeyeh, F. Eisvand, T. Sathyapalan, M. Hashemzaei, and A. Sahebkar, "Effects of curcumin on ion channels and pumps: a review," IUBMB Life, vol. 71, no. 7, pp. 812-820, 2019.

[129] V. Vauthier, C. Housset, and T. Falguieres, "Targeted pharmacotherapies for defective ABC transporters," Biochemical Pharmacology, vol. 136, pp. 1-11, 2017.

[130] S. U. Seo, S. M. Woo, H. S. Lee, S. H. Kim, K. J. Min, and T. K. Kwon, "mTORC1/2 inhibitor and curcumin induce apoptosis through lysosomal membrane permeabilizationmediated autophagy," Oncogene, vol. 37, no. 38, pp. 52055220, 2018. 
[131] W. Bursch, F. Oberhammer, and R. Schulte-Hermann, "Cell death by apoptosis and its protective role against disease," Trends in Pharmacological Sciences, vol. 13, no. 6, pp. 245251, 1992.

[132] W.-C. Chen, Y.-A. Lai, Y.-C. Lin et al., "Curcumin suppresses doxorubicin-induced epithelial-mesenchymal transition via the inhibition of TGF- $\beta$ and PI3K/AKT signaling pathways in triple-negative breast cancer cells," Journal of Agricultural and Food Chemistry, vol. 61, no. 48, pp. 11817-11824, 2013.

[133] B. R. Seo, K. J. Min, I. J. Cho, S. C. Kim, and T. K. Kwon, "Curcumin significantly enhances dual PI3K/Akt and mTOR inhibitor NVP-BEZ235-induced apoptosis in human renal carcinoma Caki cells through down-regulation of p53dependent Bcl-2 expression and inhibition of Mcl-1 protein stability," PLoS One, vol. 9, no. 4, p. e95588, 2014.

[134] M. S. Squires, E. A. Hudson, L. Howells et al., "Relevance of mitogen activated protein kinase (MAPK) and phosphotidylinositol-3-kinase/protein kinase B (PI3K/PKB) pathways to induction of apoptosis by curcumin in breast cells," Biochemical Pharmacology, vol. 65, no. 3, pp. 361-376, 2003.

[135] X. Xu, J. Qin, and W. Liu, "Curcumin inhibits the invasion of thyroid cancer cells via down-regulation of PI3K/Akt signaling pathway," Gene, vol. 546, no. 2, pp. 226-232, 2014.

[136] M. Laplante and D. M. Sabatini, "mTOR signaling," Cold Spring Harbor Perspectives in Biology, vol. 4, no. 2, 2012.

[137] M. Laplante and D. M. Sabatini, "mTOR signaling in growth control and disease," Cell, vol. 149, no. 2, pp. 274293, 2012.

[138] J. Zhang, J. Wang, J. Xu et al., "Curcumin targets the TFEBlysosome pathway for induction of autophagy," Oncotarget, vol. 7, no. 46, pp. 75659-75671, 2016.

[139] C. Settembre, C. Di Malta, V. A. Polito et al., "TFEB links autophagy to lysosomal biogenesis," Science, vol. 332, no. 6036, pp. 1429-1433, 2011.

[140] C. Settembre, R. Zoncu, D. L. Medina et al., "A lysosome-tonucleus signalling mechanism senses and regulates the lysosome via mTOR and TFEB," The EMBO Journal, vol. 31, no. 5, pp. 1095-1108, 2012.

[141] J. X. Song, Y. R. Sun, I. Peluso et al., "A novel curcumin ana$\log$ binds to and activates TFEB in vitro and in vivo independent of MTOR inhibition," Autophagy, vol. 12, no. 8, pp. 1372-1389, 2016.

[142] L. T. Yi, S. Q. Dong, S. S. Wang et al., "Curcumin attenuates cognitive impairment by enhancing autophagy in chemotherapy," Neurobiology of Disease, vol. 136, article 104715, 2020.

[143] P. A. Andreux, R. H. Houtkooper, and J. Auwerx, "Pharmacological approaches to restore mitochondrial function," Nature Reviews Drug Discovery, vol. 12, no. 6, pp. 465-483, 2013.

[144] E. Deas, N. W. Wood, and H. Plun-Favreau, "Mitophagy and Parkinson's disease: The PINK1-parkin link," Biochimica et Biophysica Acta (BBA) - Molecular Cell Research, vol. 1813, no. 4, pp. 623-633, 2011.

[145] P. Picone, D. Nuzzo, L. Caruana, V. Scafidi, and M. Di Carlo, "Mitochondrial dysfunction: different routes to Alzheimer's disease therapy," Oxidative Medicine and Cellular Longevity, vol. 2014, 11 pages, 2014.

[146] G. W. Dorn and S. J. Matkovich, "Epitranscriptional regulation of cardiovascular development and disease," The Journal of Physiology, vol. 593, no. 8, pp. 1799-1808, 2015.
[147] M. Zamora, R. Pardo, and J. A. Villena, "Pharmacological induction of mitochondrial biogenesis as a therapeutic strategy for the treatment of type 2 diabetes," Biochemical Pharmacology, vol. 98, no. 1, pp. 16-28, 2015.

[148] R. C. Scarpulla, "Metabolic control of mitochondrial biogenesis through the PGC-1 family regulatory network," Biochimica et Biophysica Acta, vol. 1813, no. 7, pp. 1269-1278, 2011.

[149] K. Sakamoto, T. Murata, H. Chuma, M. Hori, and H. Ozaki, "Fluvastatin prevents vascular hyperplasia by inhibiting phenotype modulation and proliferation through extracellular signal-regulated kinase 1 and 2 and p38 mitogen-activated protein kinase inactivation in organ-cultured artery," Arteriosclerosis, Thrombosis, and Vascular Biology, vol. 25, no. 2, pp. 327-333, 2005.

[150] C. Canto and J. Auwerx, "Caloric restriction, SIRT1 and longevity," Trends in Endocrinology and Metabolism, vol. 20, no. 7, pp. 325-331, 2009.

[151] C. Canto and J. Auwerx, "PGC-1 $\alpha$, SIRT1 and AMPK, an energy sensing network that controls energy expenditure," Current Opinion in Lipidology, vol. 20, no. 2, pp. 98-105, 2009.

[152] C. Canto, Z. Gerhart-Hines, J. N. Feige et al., "AMPK regulates energy expenditure by modulating $\mathrm{NAD}^{+}$metabolism and SIRT1 activity," Nature, vol. 458, no. 7241, pp. 10561060, 2009.

[153] Z. Gerhart-Hines, J. T. Rodgers, O. Bare et al., "Metabolic control of muscle mitochondrial function and fatty acid oxidation through SIRT1/PGC-1 $\alpha$," The EMBO Journal, vol. 26, no. 7, pp. 1913-1923, 2007.

[154] C. Handschin and B. M. Spiegelman, "Peroxisome proliferatoractivated receptor $\gamma$ coactivator 1 coactivators, energy homeostasis, and metabolism," Endocrine Reviews, vol. 27, no. 7, pp. 728-735, 2006.

[155] J.Lin, P. Puigserver, J. Donovan, P. Tarr, and B. M. Spiegelman, "Peroxisome proliferator-activated receptor gamma coactivator 1beta (PGC-1beta), a novel PGC-1-related transcription coactivator associated with host cell factor," The Journal of Biological Chemistry, vol. 277, no. 3, pp. 16451648, 2002.

[156] P. Puigserver, J. Ribot, F. Serra et al., "Involvement of the retinoblastoma protein in brown and white adipocyte cell differentiation: Functional and physical association with the adipogenic transcription factor $\mathrm{C} / \mathrm{EBP} \alpha$, European Journal of Cell Biology, vol. 77, no. 2, pp. 117-123, 1998.

[157] J. Athale, A. Ulrich, N. Chou MacGarvey et al., "Nrf2 promotes alveolar mitochondrial biogenesis and resolution of lung injury in_Staphylococcus aureus_pneumonia in mice," Free Radical Biology \& Medicine, vol. 53, no. 8, pp. 15841594, 2012.

[158] N. C. MacGarvey, H. B. Suliman, R. R. Bartz et al., “Activation of mitochondrial biogenesis by heme oxygenase-1mediated NF-E2-related factor-2 induction rescues mice from lethal Staphylococcus aureus sepsis," American Journal of Respiratory and Critical Care Medicine, vol. 185, no. 8, pp. 851-861, 2012.

[159] C. A. Piantadosi, M. S. Carraway, A. Babiker, and H. B. Suliman, "Heme oxygenase-1 regulates cardiac mitochondrial biogenesis via Nrf2-mediated transcriptional control of nuclear respiratory factor-1," Circulation Research, vol. 103, no. 11, pp. 1232-1240, 2008.

[160] S. N. Schreiber, D. Knutti, K. Brogli, T. Uhlmann, and A. Kralli, "The transcriptional coactivator PGC-1 regulates 
the expression and activity of the orphan nuclear receptor estrogen-related receptor alpha (ERRalpha)," The Journal of Biological Chemistry, vol. 278, no. 11, pp. 9013-9018, 2003.

[161] C. A. Virbasius, J. V. Virbasius, and R. C. Scarpulla, "NRF-1, an activator involved in nuclear-mitochondrial interactions, utilizes a new DNA-binding domain conserved in a family of developmental regulators," Genes \& Development, vol. 7, no. 12a, pp. 2431-2445, 1993.

[162] J. V. Virbasius, C. A. Virbasius, and R. C. Scarpulla, "Identity of GABP with NRF-2, a multisubunit activator of cytochrome oxidase expression, reveals a cellular role for an ETS domain activator of viral promoters," Genes \& Development, vol. 7, no. 3, pp. 380-392, 1993.

[163] Q. Zhang, Y. Wu, P. Zhang et al., "Exercise induces mitochondrial biogenesis after brain ischemia in rats," Neuroscience, vol. 205, pp. 10-17, 2012.

[164] R. Anderson and T. Prolla, "PGC- $1 \alpha$ in aging and anti-aging interventions," Biochimica et Biophysica Acta (BBA) - General Subjects, vol. 1790, no. 10, pp. 1059-1066, 2009.

[165] C. Canugovi, S. Maynard, A. C. V. Bayne et al., “The mitochondrial transcription factor A functions in mitochondrial base excision repair," DNA Repair, vol. 9, no. 10, pp. 10801089, 2010.

[166] R. P. Fisher and D. A. Clayton, "Purification and characterization of human mitochondrial transcription factor 1," Molecular and Cellular Biology, vol. 8, no. 8, pp. 3496-3509, 1988.

[167] S. D. Chen, D. I. Yang, T. K. Lin, F. Z. Shaw, C. W. Liou, and Y. C. Chuang, "Roles of oxidative stress, apoptosis, PGC- $1 \alpha$ and mitochondrial biogenesis in cerebral ischemia," International Journal of Molecular Sciences, vol. 12, no. 10, pp. 7199$7215,2011$.

[168] M. I. Ekstrand, M. Falkenberg, A. Rantanen et al., "Mitochondrial transcription factor A regulates mtDNA copy number in mammals," Human Molecular Genetics, vol. 13, no. 9, pp. 935-944, 2004.

[169] A. Picca and A. M. S. Lezza, "Regulation of mitochondrial biogenesis through TFAM-mitochondrial DNA interactions: useful insights from aging and calorie restriction studies," Mitochondrion, vol. 25, pp. 67-75, 2015.

[170] U. Hani and H. G. Shivakumar, "Solubility enhancement and delivery systems of curcumin a herbal medicine: a review," Current Drug Delivery, vol. 11, no. 6, pp. 792-804, 2014.

[171] M. M. Yallapu, P. K. Bhusetty Nagesh, M. Jaggi, and S. C. Chauhan, "Therapeutic applications of curcumin nanoformulations," The AAPS Journal, vol. 17, no. 6, pp. 1341-1356, 2015.

[172] M. S. Zaman, N. Chauhan, M. M. Yallapu et al., "Curcumin nanoformulation for cervical cancer treatment," Scientific Reports, vol. 6, no. 1, 2016.

[173] J. Lone, J. H. Choi, S. W. Kim, and J. W. Yun, "Curcumin induces brown fat-like phenotype in 3T3-L1 and primary white adipocytes," The Journal of Nutritional Biochemistry, vol. 27, pp. 193-202, 2016.

[174] Q. Ma, "Role of Nrf 2 in oxidative stress and toxicity," Annual Review of Pharmacology and Toxicology, vol. 53, no. 1, pp. 401-426, 2013.

[175] M. Negrette-Guzman, W. R. Garcia-Nino, E. Tapia et al., "Curcumin attenuates gentamicin-induced kidney mitochondrial alterations: possible role of a mitochondrial biogenesis mechanism," Evidence-based Complementary and Alternative Medicine, vol. 2015, 16 pages, 2015.
[176] R. D. Ray Hamidie, T. Yamada, R. Ishizawa, Y. Saito, and K. Masuda, "Curcumin treatment enhances the effect of exercise on mitochondrial biogenesis in skeletal muscle by increasing cAMP levels," Metabolism, vol. 64, no. 10, pp. 1334-1347, 2015.

[177] L. Liu, W. Zhang, L. Wang et al., "Curcumin prevents cerebral ischemia reperfusion injury via increase of mitochondrial biogenesis," Neurochemical Research, vol. 39, no. 7, pp. 1322-1331, 2014.

[178] Z. Song, X. Revelo, W. Shao et al., "Dietary curcumin intervention targets mouse white adipose tissue inflammation and brown adipose tissue UCP1 expression," Obesity (Silver Spring), vol. 26, no. 3, pp. 547-558, 2018.

[179] K. Palikaras, E. Lionaki, and N. Tavernarakis, "Mitophagy: in sickness and in health," Molecular \& Cellular Oncology, vol. 3, no. 1, p. e1056332, 2015.

[180] K. Palikaras and N. Tavernarakis, "Mitochondrial homeostasis: the interplay between mitophagy and mitochondrial biogenesis," Experimental Gerontology, vol. 56, pp. 182-188, 2014.

[181] T. M. Durcan and E. A. Fon, "The three "P"s of mitophagy: PARKIN, PINK1, and post-translational modifications," Genes \& Development, vol. 29, no. 10, pp. 989-999, 2015.

[182] T. M. Durcan and E. A. Fon, "USP8 and PARK2/parkinmediated mitophagy," Autophagy, vol. 11, no. 2, pp. 428429, 2015.

[183] M. Song, G. Gong, Y. Burelle et al., "Interdependence of Parkin-mediated mitophagy and mitochondrial fission in adult mouse hearts," Circulation Research, vol. 117, no. 4, pp. 346-351, 2015.

[184] L.-S. Chin and L. Li, "Ubiquitin phosphorylation in Parkinson's disease: implications for pathogenesis and treatment," Translational Neurodegeneration, vol. 5, no. 1, 2016.

[185] M. H. Irwin, W. H. Moos, D. V. Faller, K. Steliou, and C. A. Pinkert, "Epigenetic treatment of neurodegenerative disorders: Alzheimer and Parkinson diseases," Drug Development Research, vol. 77, no. 3, pp. 109-123, 2016.

[186] S. Rajagopalan, A. Rane, S. J. Chinta, and J. K. Andersen, "Regulation of ATP13A2 via PHD2-HIF1 $\alpha$ signaling is critical for cellular iron homeostasis: implications for Parkinson's disease," The Journal of Neuroscience, vol. 36, no. 4, pp. 10861095, 2016.

[187] M. Tong and J. Sadoshima, "Mitochondrial autophagy in cardiomyopathy," Current Opinion in Genetics \& Development, vol. 38, pp. 8-15, 2016.

[188] C. Wang, X. Zhang, Z. Teng, T. Zhang, and Y. Li, “Downregulation of PI3K/Akt/mTOR signaling pathway in curcumininduced autophagy in APP/PS1 double transgenic mice," European Journal of Pharmacology, vol. 740, pp. 312-320, 2014.

[189] X. Wang, A. W. Leung, J. Luo, and C. Xu, "TEM observation of ultrasound-induced mitophagy in nasopharyngeal carcinoma cells in the presence of curcumin," Experimental and Therapeutic Medicine, vol. 3, no. 1, pp. 146-148, 2012.

[190] J. Chen, T. Xu, and C. Chen, "The critical roles of miR-21 in anti-cancer effects of curcumin," Annals of Translational Medicine, vol. 3, no. 21, p. 330, 2015.

[191] J. Zhang, Y. Du, C. Wu et al., "Curcumin promotes apoptosis in human lung adenocarcinoma cells through miR-186 signaling pathway," Oncology Reports, vol. 24, no. 5, pp. 12171223, 2010. 
[192] A. A. Momtazi, F. Shahabipour, S. Khatibi, T. P. Johnston, M. Pirro, and A. Sahebkar, "Curcumin as a microRNA regulator in cancer: a review," Reviews of Physiology, Biochemistry and Pharmacology, vol. 171, pp. 1-38, 2016.

[193] H. Mirzaei, A. Masoudifar, A. Sahebkar et al., "MicroRNA: a novel target of curcumin in cancer therapy," Journal of Cellular Physiology, vol. 233, no. 4, pp. 3004-3015, 2018.

[194] J. Baell and M. A. Walters, "Chemistry: chemical con artists foil drug discovery,” Nature, vol. 513, no. 7519, pp. 481483, 2014.

[195] J. B. Baell and G. A. Holloway, "New substructure filters for removal of pan assay interference compounds (PAINS) from screening libraries and for their exclusion in bioassays," Journal of Medicinal Chemistry, vol. 53, no. 7, pp. 2719-2740, 2010.

[196] Y. Hu and J. Bajorath, "Compound promiscuity: what can we learn from current data?," Drug Discovery Today, vol. 18, no. 13-14, pp. 644-650, 2013.

[197] K. M. Nelson, J. L. Dahlin, J. Bisson, J. Graham, G. F. Pauli, and M. A. Walters, "The essential medicinal chemistry of curcumin," Journal of Medicinal Chemistry, vol. 60, no. 5, pp. 1620-1637, 2017.

[198] K. M. Nelson, J. L. Dahlin, J. Bisson, J. Graham, G. F. Pauli, and M. A. Walters, "Curcumin may (not) defy science," ACS Medicinal Chemistry Letters, vol. 8, no. 5, pp. 467-470, 2017.

[199] G. Padmanaban and V. A. Nagaraj, "Curcumin may defy medicinal chemists," ACS Medicinal Chemistry Letters, vol. 8 , no. 3, p. 274, 2017.

[200] A. B. Kunnumakkara, D. Bordoloi, G. Padmavathi et al., "Curcumin, the golden nutraceutical: multitargeting for multiple chronic diseases," British Journal of Pharmacology, vol. 174, no. 11, pp. 1325-1348, 2017.

[201] S. Richard, A. Saric, M. Boucher et al., "Antioxidative theranostic iron oxide nanoparticles toward brain tumors imaging and ROS production," ACS Chemical Biology, vol. 11, no. 10, pp. 2812-2819, 2016.

[202] M. Suzuki, L. Bachelet-Violette, F. Rouzet et al., "Ultrasmall superparamagnetic iron oxide nanoparticles coated with fucoidan for molecular MRI of intraluminal thrombus," Nanomedicine (London, England), vol. 10, no. 1, pp. 73-87, 2015.

[203] S. S. Hann, J. Chen, Z. Wang, J. Wu, F. Zheng, and S. Zhao, "Targeting EP4 by curcumin through cross talks of AMPdependent kinase alpha and p38 mitogen-activated protein kinase signaling: the role of PGC- $1 \alpha$ and Sp1," Cellular Signalling, vol. 25, no. 12, pp. 2566-2574, 2013.

[204] M. M. Rechtman, O. Har-Noy, I. Bar-Yishay et al., "Curcumin inhibits hepatitis $B$ virus via down-regulation of the metabolic coactivator PGC-1 $\alpha$, FEBS Letters, vol. 584, no. 11, pp. 2485-2490, 2010.

[205] P. Du, H. Cao, H. R. Wu et al., "Blocking Bcl-2 leads to autophagy activation and cell death of the HEPG2 liver cancer cell line," Asian Pacific Journal of Cancer Prevention, vol. 14, no. 10, pp. 5849-5854, 2013.

[206] A. Hematulin, K. Ingkaninan, N. Limpeanchob, and D. Sagan, "Ethanolic extract from Derris scandens Benth mediates radiosensitzation via two distinct modes of cell death in human colon cancer HT-29 cells," Asian Pacific Journal of Cancer Prevention, vol. 15, no. 4, pp. 1871-1877, 2014.
[207] Y. Wan, Y. Liang, F. Liang et al., "A curcumin analog reduces levels of the Alzheimer's disease-associated Amyloid- $\beta$ protein by modulating $\mathrm{A} \beta \mathrm{PP}$ processing and autophagy," Journal of Alzheimer's Disease, vol. 72, no. 3, pp. 761-771, 2019.

[208] S. Vijayarathna, S. Gothai, S. L. Jothy, Y. Chen, J. R. Kanwar, and S. Sasidharan, "Can cancer therapy be achieved by bridging apoptosis and autophagy: a method based on microRNA-dependent gene therapy and phytochemical targets," Asian Pacific Journal of Cancer Prevention, vol. 16, no. 17, pp. 7435-7439, 2015.

[209] S. Vijayarathna, C. Oon, S. Jothy, Y. Chen, J. Kanwar, and S. Sasidharan, "MicroRNA pathways: an emerging role in identification of therapeutic strategies," Current Gene Therapy, vol. 14, no. 2, pp. 112-120, 2014.

[210] A. Pavan, G. Silva, D. Jornada et al., "Unraveling the anticancer effect of curcumin and resveratrol," Nutrients, vol. 8, no. 11, p. 628, 2016.

[211] Y.-J. Chang, C. Y. Huang, C. S. Hung, W. Y. Chen, and P. L. Wei, "GRP78 mediates the therapeutic efficacy of curcumin on colon cancer," Tumour Biology, vol. 36, no. 2, pp. 633641, 2015.

[212] L. X. Chen, Y. J. He, S. Z. Zhao et al., "Inhibition of tumor growth and vasculogenic mimicry by curcumin through down-regulation of the EphA2/PI3K/MMP pathway in a murine choroidal melanoma model," Cancer Biology \& Ther$a p y$, vol. 11, no. 2, pp. 229-235, 2014.

[213] C. Q. Chen, K. Yu, Q. X. Yan et al., "Pure curcumin increases the expression of SOCS1 and SOCS3 in myeloproliferative neoplasms through suppressing class $I$ histone deacetylases," Carcinogenesis, vol. 34, no. 7, pp. 1442-1449, 2013.

[214] B. Chen, Y. Zhang, Y. Wang, J. Rao, X. Jiang, and Z. Xu, "Curcumin inhibits proliferation of breast cancer cells through Nrf2-mediated down-regulation of Fen1 expression," The Journal of Steroid Biochemistry and Molecular Biology, vol. 143, pp. 11-18, 2014.

[215] S. M. Gao, J. J. Yang, C. Q. Chen et al., "Pure curcumin decreases the expression of WT1 by upregulation of miR15a and miR-16-1 in leukemic cells," Journal of Experimental \& Clinical Cancer Research, vol. 31, no. 1, p. 27, 2012.

[216] Y. Guo, L. Shu, C. Zhang, Z. Y. Su, and A. N. T. Kong, "Curcumin inhibits anchorage-independent growth of HT29 human colon cancer cells by targeting epigenetic restoration of the tumor suppressor gene_DLEC1_,"Biochemical Pharmacology, vol. 94, no. 2, pp. 69-78, 2015.

[217] L. Wang, X. Ye, X. Cai et al., "Curcumin suppresses cell growth and invasion and induces apoptosis by downregulation of Skp2 pathway in glioma cells," Oncotarget, vol. 6, no. 20, pp. 18027-18037, 2015.

[218] Z. Zhao, C. Li, H. Xi, Y. Gao, and D. Xu, "Curcumin induces apoptosis in pancreatic cancer cells through the induction of forkhead box O1 and inhibition of the PI3K/Akt pathway," Molecular Medicine Reports, vol. 12, no. 4, pp. 5415-5422, 2015.

[219] M. Jiang, O. Huang, X. Zhang et al., "Curcumin induces cell death and restores tamoxifen sensitivity in the antiestrogenresistant breast cancer cell lines MCF-7/LCC2 and MCF7/LCC9," Molecules, vol. 18, no. 1, pp. 701-720, 2013.

[220] M. Sun, Z. Estrov, Y. Ji, K. R. Coombes, D. H. Harris, and R. Kurzrock, "Curcumin (diferuloylmethane) alters the expression profiles of microRNAs in human pancreatic 
cancer cells," Molecular Cancer Therapeutics, vol. 7, no. 3, pp. 464-473, 2008.

[221] S. Ali, A. Ahmad, S. Banerjee et al., "Gemcitabine sensitivity can be induced in pancreatic cancer cells through modulation of miR-200 and miR-21 expression by curcumin or its analogue CDF," Cancer Research, vol. 70, no. 9, pp. 3606-3617, 2010.

[222] G. Mudduluru, J. N. George-William, S. Muppala et al., "Curcumin regulates miR-21 expression and inhibits invasion and metastasis in colorectal cancer," Bioscience Reports, vol. 31, no. 3, pp. 185-197, 2011.

[223] J. Yang, Y. Cao, J. Sun, and Y. Zhang, "Curcumin reduces the expression of Bcl-2 by upregulating miR-15a and miR-16 in MCF-7 cells," Medical Oncology, vol. 27, no. 4, pp. 1114$1118,2010$.

[224] N. Wang, T. Feng, X. Liu, and Q. Liu, "Curcumin inhibits migration and invasion of non-small cell lung cancer cells through up-regulation of miR-206 and suppression of PI3K/AKT/mTOR signaling pathway," Acta Pharmaceutica, vol. 70, no. 3, pp. 399-409, 2020.

[225] Y. Li, Y. Gu, N. Tang, Y. Liu, and Z. Zhao, "miR-22-Notch signaling pathway is involved in the regulation of the apoptosis and autophagy in human ovarian cancer cells," Biological \& Pharmaceutical Bulletin, vol. 41, no. 8, pp. 1237-1242, 2018.

[226] Z. Han, J. Zhang, K. Zhang, and Y. Zhao, "Curcumin inhibits cell viability, migration, and invasion of thymic carcinoma cells via downregulation of microRNA-27a," Phytotherapy Research, 2020.

[227] L. Zhou, Y. Lu, J. S. Liu et al., "The role of miR-21/RECK in the inhibition of osteosarcoma by curcumin," Molecular and Cellular Probes, vol. 51, p. 101534, 2020.

[228] S. Sreenivasan, K. Thirumalai, R. Danda, and S. Krishnakumar, "Effect of curcumin on miRNA expression in human Y79 retinoblastoma cells," Current Eye Research, vol. 37, no. 5, pp. 421-428, 2012. 